Jovana Jankovic

Supervised by Dr. Jennifer Brayton

The Major Research Paper is submitted in partial fulfillment of the requirements for the degree of Master of Arts

Joint Graduate Program in Communication \& Culture Ryerson University - York University

Toronto, Ontario, Canada

May 10,2013 


\section{AUTHOR'S DECLARATION}

I hereby declare that I am the sole author of this MRP. This is a true copy of the MRP, including any required final revisions.

I authorize Ryerson University to lend this MRP to other institutions or individuals for the purpose of scholarly research.

I further authorize Ryerson University to reproduce this MRP by photocopying or by other means, in total or in part, at the request of other institutions or individuals for the purpose of scholarly research.

1 understand that my MRP may be made electronically available to the public. 


\title{
CONSTRUCTING IDENTITIES THROUGH MUSIC VIDEOS: A CASE STUDY ANALYSIS OF TEGAN AND SARA'S MUSIC VIDEOS
}

\author{
Jovana Jankovic, 2013 \\ Master of Arts \\ Communication and Culture Graduate Program \\ Ryerson University
}

\begin{abstract}
"I believe that our music does not have sexuality," proclaimed Sara of Tegan and Sara, in an interview for The Advocate (2005). This paper argues that Tegan and Sara's music videos do in fact contain elements that reflect their sexuality, and examines the extent to which these videos demonstrate their public identity. In order to understand the composition of music videos and the nonverbal signs related to gender and sexuality within them, 1 draw upon theories of performed identity, music video genres, settings, and lyrical analysis. In examining three of Tegan and Sara's music videos, "The First" (2000), "Back In Your Head" (2007), and "Closer" (2012), I present a narrative structure of their musical career, and outline how their approach and portrayal of their sexual orientation has evolved over the thirteen years they have been together as a band. The results show that Tegan and Sara have increasingly embraced their gender and sexuality over time.
\end{abstract}




\section{ACKNOWLEDGMENTS}

It would not have been possible to write this Major Research Paper without the help and support of the compassionate people around me. First I would like to thank Dr. Jennifer Brayton for her support and guidance, and Dr. Robert Bowman for his time and insight. Their expertise and valuable advice helped keep me on track and solidify this paper. My gratitude goes out as well to all the staff and faculty in the Communication and Culture department for their counsel and contribution. Lastly 1 wish to thank my family and close friends for their patience, enthusiasm, and interest in this project. You have given me the motivation to realize this achievement. 


\section{CHAPTER I: Public Identity and Music Videos}

1.1 Introduction.

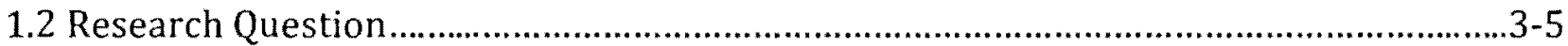

1.3 Methodology

\section{CHAPTER II: The Background and History of Tegan and Sara and "Tegan and Sara"}

2.1 Who are "Tegan and Sara"?

2.1.1 Influences

2.1.2 Management.

2.1.3 Evolution

2.2 Who are Tegan and Sara?

2.2.1 Tensions with the Media.

2.2.2 Relationship with Fans.

\section{CHAPTER III: Case Study Analysis of Tegan \& Sara's Music Videos}

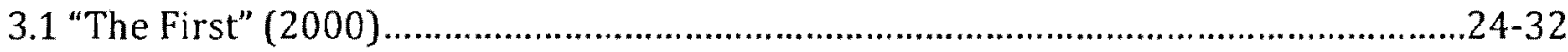

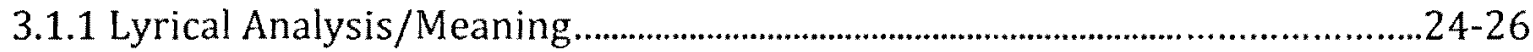

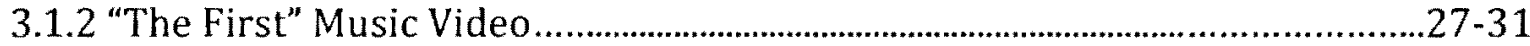

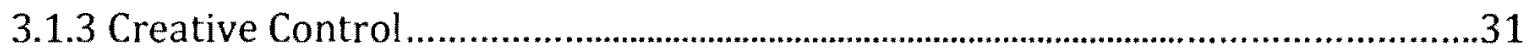

3.1.4 "The First" Summary ……….................................................................................

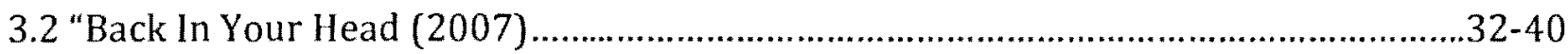

3.2.1 Lyrical Analysis/Meaning........................................................................................33-34

3.2.2 "Back In Your Head" Music Video.............................................................................34-38

3.2.3 Creative Contribution.............................................................................................38-39

3.2.4 "Back In Your Head" Summary ..................................................................................39-40

3.3 "Closer" (2012)

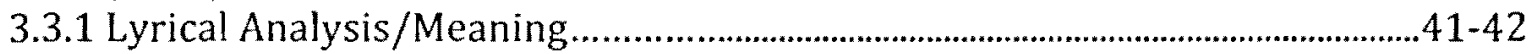

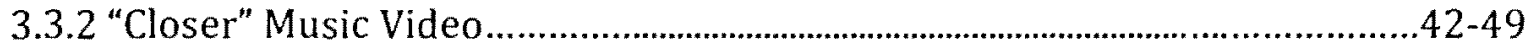

3.3.3 Creative Contribution........................................................................................

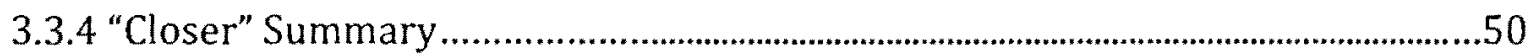

\section{CHAPTER IV: MAKING THE CONNECTION}

Conclusion 


\section{APPENDICES}

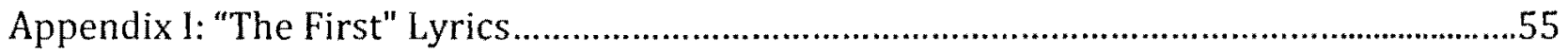

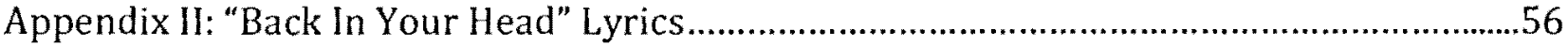

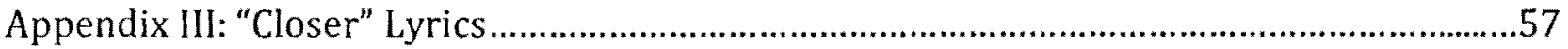

WORKS CITED

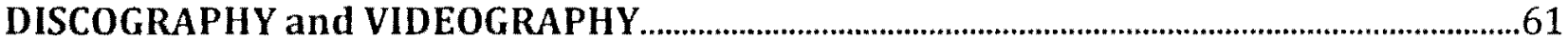




\section{LIST OF IMAGES}

lmage 1: Tegan and Sara at Warner Brothers office.........................................................................14

Image 2: Tegan and Sara fan photographs on Facebook.................................................................21

Image 3: Screen shot of "The First" music video .................................................................................29

Image 4: Screen shot of "Back In Your Head" music video.....................................................................36

Image 5: Screen shot of audience, "Back In Your Heard" music video .....................................38

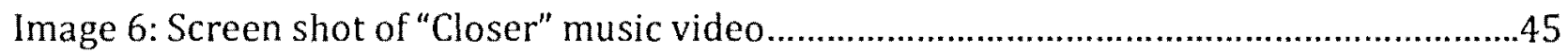




\section{Chapter I: Public Identity and Music Videos}

\subsection{INTRODUCTION}

"For people to trust you and believe you, they have to see you a little bit. I'm not afraid to expose myself in that way," explains Sara of Tegan and Sara, in an interview with Amanda Ash for Exclaim.ca. One way for musicians to expose themselves is through music videos. The role of music videos in our current cultural context is constantly changing. By making an auditory experience visual, music videos are primarily used to promote an album and/or artist. Coming into prominence in the 1980 s, music videos were initially perceived as commercials, used to sell a single, record, or performer. "Because music videos are not only a form of entertainment, but also a means of advertising, ultimately created to sell a product, their images are intended to be especially powerful and captivating" (Wallis 161). While it is important to acknowledge that music videos can affect viewers' conceptions of acceptable sexual behaviour and gender stereotypes (Wallis 164), my research focus is on the performed identity within music videos, rather than the interpretation of it by the audience.

Music videos allow artists to present desired interpretations of their songs to their audiences by combining imagery with music. Hence, while music videos inevitably promote the artist(s) and their album, in many cases they are also an art form, allowing musicians to express themselves in the visual realm and thus create a public identity. Public identity in this paper will refer to the identity that is intentionally created and managed by musicians through the media. This can involve the expression that he/she gives, and the expression that he/she gives off (Goffman 2). According to sociologist Erving Goffman, the first type of expressiveness involves verbal symbols to convey the information symbolically. The second involves a wide range of action that others can treat as symptomatic of the actor. "The 
individual does of course intentionally convey misinformation by means of both of these types of communication" (Goffman 2).

Popular music artists, such as Tegan and Sara, are often viewed as role models. "In the early days, our experiences felt very authentic for people, and for kids, like us, who didn't necessarily have a ton of gay role models, or people that they were looking up to" (Sara qtd. in "Tegan and Sara Interview. Music-News.com, Heartthrobs"). Tegan feels a responsibility to be outspoken on behalf of the LGBT community. "I absolutely feel a responsibility to be out and be confident, which we've always been. And I know that the majority of our audience respects us and looks up to us because of what we believe in" (Shechet). I will be using this iconic Canadian indie/pop band to serve as an example in demonstrating the extent to which sexuality and sexual orientation can be found in music videos, and trace the evolution of Tegan and Sara's public identity from independent artists to signed musicians with a label. In exploring the representation of their sexual orientation I will be examining their displays of sexuality and depiction of gendered roles.

While Tegan and Sara are both openly lesbian, they do not believe their music needs to reflect this. "We're proud to be gay, but I believe that our music does not have sexuality" (Sara qtd. in Marcus). Both Tegan and Sara have expressed their wish for the press to stop fixating on their sexuality in numerous interviews. "It's always, "Tegan and Sara's new records, they're gay, gay, gay, gay, gay, big fat gay, gay, gay," says Sara. "If it's an interview or an article in the gay press, that's OK. But why, in a review of a record does it have to talk about us being gay?" (Marcus). Their goal, they say, is to make music for everyone and they want everyone to focus on their music, not their sexual orientation. However, it may prove challenging for fans and 
the media to dissociate the artists' public identity, part of which is at least partially comprised of their sexuality, from their music.

Throughout this paper I will argue that despite Tegan and Sara's efforts to disconnect their sexuality from their music, it is inevitable that their music videos will contain elements that innately and intimately reflect their sexuality. Even if Tegan and Sara unintentionally paint a picture of themselves that represents their sexuality in a specific way, it is necessary for them to address and embrace it, as the fans and media will be influenced by it regardless. Furthermore, an analysis of sexuality and gender display in Tegan and Sara's music videos can potentially provide knowledge of the media's role in the social construction of gender and sexuality.

\subsection{RESEARCH QUESTION}

To what extent do Tegan and Sara's music videos demonstrate their public identity and to what degree do Tegan and Sara adhere to conventional nonverbal gender and sexuality behaviours in their music videos? Along the way, I will also examine how Tegan and Sara's apparently unintentional representations of gender and sexuality in music videos compares to their verbal responses on this subject matter in interviews. The outcomes of this study could shed light on how gender and sexuality are constructed in music videos in general, and could reveal whether Tegan and Sara should reconsider their stance on addressing their sexuality, gender and sexual orientation publicly. My hypothesis is that gender and sexuality are inherently displayed in Tegan and Sara's music and music videos. It is fundamentally important that the portrayal of this sexuality be acknowledged and created with awareness by the band in order to send an intentional message to listeners/viewers. 
This paper will examine the extent to which two female performers adhere to conventional nonverbal gendered attributes and behaviours in their music videos. I have chosen to assess the music videos of three Tegan and Sara songs, "The First" (2000), "Back In Your Head" (2007), and "Closer" (2012), for several reasons. In February 2013, MusicNews.com asked Tegan and Sara to identify what three songs define and represent them best. Tegan responded without hesitation: "Walking With a Ghost", "Back In Your Head" and "Closer". In this interview Tegan explains that "Walking With a Ghost" represents them and their time when they were indie rock. "Back In Your Head" is a transitional song bridging their folk-indie rock sound to the pop world, and "Closer" is very revealing about their new sound and represents who they are as artists today ("Music-News.com, Heartthrobs").

I will be analyzing two of these three songs ("Back In Your Head" and "Closer"), in part because Tegan and Sara believe they are most representative of who they are as artists, but also because they are two of my favorite songs and music videos of Tegan and Sara's. The reason I have excluded "Walking With a Ghost" and replaced it with "The First" is due to the time it was created and released. Because I wish to examine if and how Tegan and Sara's public identity, and its portrayal in their music videos, has evolved over the thirteen years they have been together, I will be looking at their first, middle, and last music videos. Consequently, because "Walking With a Ghost" is on the same album as "Back In your Head", I believe that it will be less useful to compare the visual representation of the artists for these two songs/videos.

I have chosen to base my analysis on the music videos of Tegan and Sara for several reasons. The bands' members, identical twin sisters, Tegan Quin and Sara Quin, have grown together since the beginning of their musical careers, and their style, image, genre, and sound 
has evolved over the years. While their sexuality has remained the same, and they have selfidentified as lesbians since the beginning of their musical careers, not all of their music videos reveal this aspect of their public identity.

\subsection{METHODOLOGY}

In order to understand the composition of music videos and the nonverbal signs related to public identity within them, I will utilize Diane Railton and Paul Watson's four genres of music videos, Erving Goffman's theories on performativity and identity, Carol Vernallis' five types of settings in music videos, Simon Frith's analysis of a musician's body, and Richard Middleton's theory on the way lyrics can be shaped to music. I will apply these theories of musicology and sociology to my analysis of Tegan and Sara's music videos, to frame and support my analysis.

In order to define the band's public identity, I will include a contextual literature review, describing the band's history, discussing their style, relationship with fans, musical influences, and management. My assessment will be comprised of three sources. Firstly, various Tegan and Sara interviews in media will be examined and used as a source of knowledge about their sense of identity (especially their sexuality), and how they articulate it. Secondly, the analysis of their music, including pitch, rhythm, lyrical analysis and meaning, will be significant in declaring whether their music alone has and conveys a certain sexuality. Finally, in dissecting the nonverbal displays such as gestures, body movement, facial expressions, clothing, setting, visual metaphors, interaction amongst performers, and interaction with instruments, in Tegan and Sara's three music videos, it will shed light on whether their music videos reflect their sexuality. Gender and sexuality displays examined in these music videos will focus on the lead 
performers, Tegan and Sara, as well as other individuals present in the videos, as all visual elements can define and shape a band's public image.

In addition to this analysis, it will be important to consider who contributed to the making of each music video. Band members can be greatly involved in the production of a music video, but often it is the music video director or recording company who will have the majority of the creative control. Vernallis describes the process of video creation as record companies soliciting "treatments" from video directors that contain "a description of a mood and concept, along with supporting illustrations often cut from magazines or art books" (89). The director must then design images that match the record company's expectations. "Treatments accepted by the record company then become subject to contentious negotiations among the director, the musician, and record company personnel" (89-90). Hence, because a directorial voice can play a major role in the video-making process, it can be challenging to assess how accurately the band's self-identity is captured.

In Tegan and Sara's case, their band initially started out as an independent indie rock/pop group. During the first years of their professional musical career, they managed most aspects of their career. As time went on, and the band decided to sign with a label, and their creative control may have diminished. However, it is important to keep in mind that even if a band has little involvement in the concept and execution of their music videos, directors often take the band's image into account and attempt to deliver a video that closely resembles what they believe the band and their music is about. Furthermore, if this is not the case, Cara Wallis argues that "although most musical artists do not produce their own music videos [...] these artists are participating in the maintenance and production of the gender status quo" (169). While my research will not solely focus on gender, the same can be argued 
for other behaviours. Thus musicians are a major factor in the creation of a music video with the director and/or label.

For musicologists, Diane Railton and Paul Watson there are four genres of music video: the pseudo-documentary music video, the art music video, the narrative music video and the staged performance music video (49). I will categorize Tegan and Sara's music videos that I will be examining into these four genres, and explain if and how elements of these different genres can overlap within one music video. This process and categorization will help me distinguish between elements within music videos that are related to the band's identity.

The pseudo-documentary music video "deploys the aesthetic of documentary realism to portray the 'working-life' of the band and artist and, as such, functions to legitimate them as skilled, professional, musicians" (Railton and Watson 49). These videos serve primarily as advertisements. The video presents its events in real time, usually beginning with the commencement of a song and ending with the applause. The viewer has access to multiple shots of the crowd as well, so he/she does not actually feel as though they are a part of it. Music videos of this type can give the viewer further privilege and insight into the band or artists' work, by taking him/her on a visual tour into the rehearsal studio, backstage, and on the road. There is often emphasis on and close-ups of the musicians playing the instruments. The 'art' music video appeals primarily to the notion of art and aesthetics. This type of video does not give the viewer a sense of the reality of the artist, or of the performance. It is not a video about the band but rather about the visual experience of light, colour, movement, and sound. "The art music video may in some cases also be an art work but it nevertheless remains the case that it is first and foremost a promotional video" (Railton and Watson 52). 
The 'narrative' music video tells a story using visual narration. These types of videos can "illustrate, complement or extend the lyrical content of the song, or, on the other hand, function independently of it" (Railton and Watson 55). The story can be told in various ways, drawing from various techniques in order to tell it. In some cases the video is more of a literal visualization of the lyrics, while other times it can be a combination of performance images and a fictional story.

Finally, the 'staged performance' music video embraces its promotional function. The performance is designed for the video specifically, and the performers directly address the camera while choreographed dancers can be performing in the background. Railton and Watson believe that there is no story and no art making in this type of music video. Instead it tries to portray the talent and image of the artist explicitly.

While these four genres of music videos are quite different, emphasizing and focusing on distinctive elements of the music and artist, I believe that aspects of each of these types of music videos can overlap within one music video. This can make it more difficult to label a video as any one type. In some cases, the viewer may see a story depicted in a pseudodocumentary video or art elements within a narrative music video. Although the music videos I will analyze may generally fall into one of these four music video categories, I will show how each one contains components from more than one of these music video genres.

I have decided to focus on the four most relevant aspects of a music video that I believe contribute to constructing a band's sexuality. First, I will explore the purely visual aspects of the video, including the use of colour, pattern, composition and visual metaphor, based on Ann Seward Barry and Carol Vernallis' aesthetic theories. I will then look at the band members' personal style, including dress, hair, make-up etc. I will assess the band's physical 
presence, movement, gestures and any choreography within the music video. Lastly, I will examine the band's interaction between each member and between member and instrument. By comparing my findings to the literature on Tegan and Sara's identity I hope to discover how closely these visuals reflect their public identity.

For sociologist Erving Goffman, "information about the individual helps to define the situation, enabling others to know in advance what he will expect of them and what they may expect of him" (1). In discussing performativity and identity, Goffman points out that as observers and those being observed, it is significant to be aware of the signs affiliated with certain actions, and to take into account the possibilities of misrepresented action or symbols. Individuals may deliberately or unintentionally convey misinformation. They may act in a thoroughly calculating manner, expressing him/herself in a given way in order to give an impression that is likely to evoke a specific response, or he/she may be unaware of their actions altogether (Goffman 6). In front of others, individuals often try to control the impression others receive of the situation (Goffman 15). When it comes to the performeraudience relationship, various techniques can be used by the artist to convey and maintain a certain image. It is significant to note that appearance and manner may tend to contradict each other; therefore, it is vital to assess both fashion style, and body movement and gestures, within Tegan and Sara's music videos. A performer can appear to be of higher estate than his/her audience but act in an unexpectedly egalitarian manner, or a performer can be dressed in garments of a high position, yet present him/herself to an individual of even higher status (Goffman 25). The challenge lies in correctly conveying and reading these signs, and while it is difficult enough understanding the symbols of communication face to face, it is even more complicated to decipher them through a media source. Consequently, while many of my 
interpretations are based on specific visual and verbal contexts, they can be interpreted differently by others.

Musicologist Carol Vernallis believes that "music videos do indeed create a sense of place, if only momentarily" (87). Vernallis describes five basic types of place in music videos. An extension of a performance space is often extremely detailed. A space that suggests specific acoustical properties can be an extension of the recording studio. A schematic representation of a familiar type of site can be a couch in a warehouse to suggest a living room. A composite space that combines more than one type of site within a single setting can draw our attention to contrasts within the other media. A fundamental contrast between two types of shot: one an elaborately constructed setting, and the other an empty shot with a simple backdrop, for example, a complicated set with many figures with a plain background gives music videos a degree of psychological complexity. Lastly, a series of sites that culminate in a final destination like a party or the beach, such as a room after room or location after location - often reaching a destination alluded to in the video's opening; matches the music's speed and continuity; and consists of a variety of material (Vernallis 83). I will apply these basic types of place in music videos to my case study analysis in order to determine if and how a setting contributes to gender and sexuality displays.

Simon Frith, a well-known musicologist, believes that a "musician's body is also an instrument" (Performing Rites 219). He describes this use of the body as an instrument as having two components. First, "the material we work on determines our movements" (Performing Rites 219). The instrument a musician plays determines the instrument the body must be; whether it is standing up, sitting down, blowing, hitting or pulling. Second, "our movements are also determined by our purpose" (Performing Rites 219). In other words, to 
play a certain sort of note can require a movement different from that of playing another note. Frith's theory will be used to define Tegan and Sara's interaction with their instruments, and compared against gender and sexuality display behaviours.

Richard Middleton, categorizes the way lyrics can be shaped to music. First he believes that words can function as expressive objects. They merge with the melody and the voice generating feeling. Second, words can adopt a narrative function where they govern the rhythmic and harmonic flow, and the voice generates speech. Third, words can act like sounds. Music absorbs those words that function as musical effects and as rhymes, and the voice becomes an instrument (Middleton 231). I will use Middleton's three lyrical forms diagram (see Figure 1 below), in my case study analysis to better understand the intention of lyrics within each song.

Story: words as narrative tend to govern rhythmic / harmonic flow; voice tends towards speech

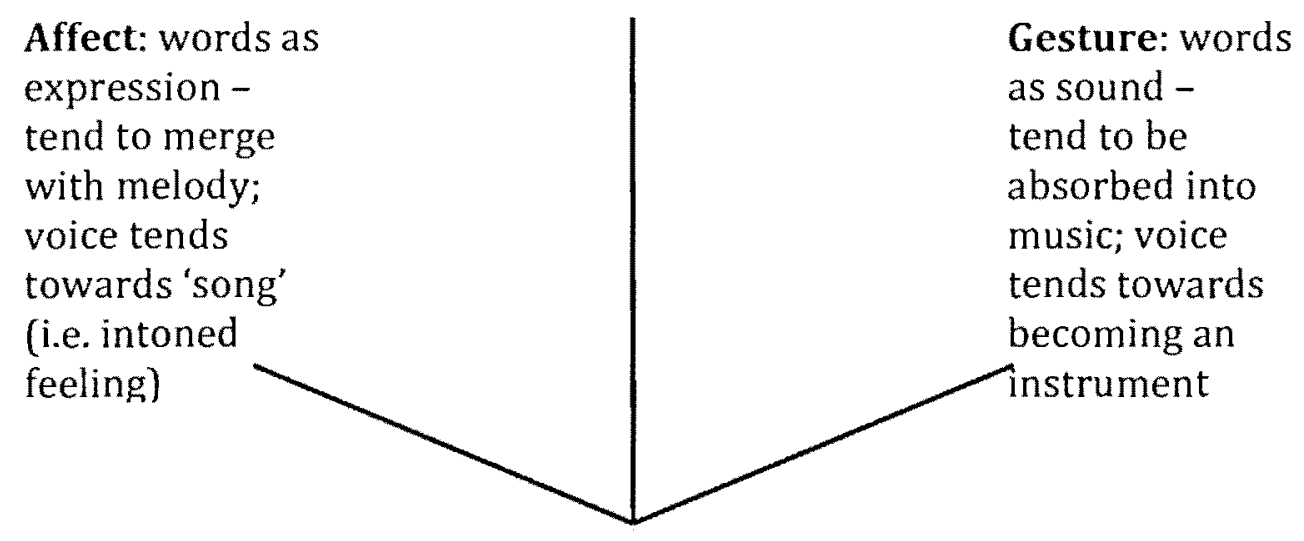

Figure 1 (Middleton, 231) 


\section{Chapter II: THE BACKSTORY OF "TEGAN AND SARA" AND TEGAN AND SARA}

\subsection{WHO ARE "TEGAN AND SARA"?}

This chapter will examine "Tegan and Sara" and Tegan and Sara. Because they are twins who are in a band together, Tegan and Sara's individuality as two female performers is often overlooked by the media. Therefore, it is important to acknowledge "Tegan and Sara" as a band, and Tegan and Sara as individuals.

Tegan and Sara Quin are twins, born in Calgary, AB in 1980. They began playing guitar and writing songs at age fifteen and have been playing together under the name "Tegan and Sara" since 1999. Their current backing musicians include Ted Gowans (guitar), Jasper Leak (bass), John Spence (keyboards), and Jason McGerr (drums). In April 1998, while the sisters were still in high school, they entered Garage Warz, a battle of the bands competition, and received one of the highest scores in history (Ash). With their historic victory, they won studio time and began performing in coffee shops across Canada. Neither Tegan nor Sara knew what they wanted to do upon graduating high school, so they continued playing at coffee shops and sports bars. They learned the ropes on the road and became stronger songwriters. "Tegan and Sara" gradually worked their way up to performing at clubs and on small stages - even collaborating with artists such as Tiesto, David Guetta and Morgan Page. Together they have released six records over ten years. The Canadian indie rock / indie pop duo is now blending the pop and indie worlds to go more "mainstream". Having sold nearly one million career albums, they just released their seventh studio album Heartthrob on January 29, 2013.

\subsubsection{Influences}

Like many artists, Tegan and Sara are influenced by what they listen to. Although at times their musical paths are parallel, they go through various phases individually. This 
musical divergence benefits them as they often try to implement their styles into each other's and often come up with a unique blend. Growing up in the 80 s and 90 s, Tegan and Sara listened to Madonna, Duran Duran, Cindy Lauper, Kate Bush, and The New Pornographers. As time went on, the music Tegan and Sara listened to became far removed from their own style. Tegan grew to appreciate hard rock and Sara became a fan of indie rock and hip-hop. As Tegan began listening to Nirvana, Smashing Pumpkins and Hole, Sara enjoyed Rhiannha, Beyonce, Alicia Keys and Robyn. Sara explains that she enjoys strong and deliberate songs. While writing songs for their latest album Heartthrob, she tried to keep her favorite artists in mind ("Music-News.com, Heartthrobs"). Perhaps because they grew up listening to pop and dance music, their music and style has naturally evolved to what it is today - a new kind of pop.

Tegan and Sara treat what they do like a job. While it is often an adventure it has always felt like a job and they believe that this is one of the reasons that they have been so successful. The two women have been criticized for thinking this way: "artists shouldn't think about the 'business!"” mocks Tegan (“Q with Jian Ghomeshi”). Although they have self-managed for years, this does not mean that they are not passionate about what they do musically. "It's the marriage of the business and passion that makes it what it is," comments Tegan ("Q with Jian Ghomeshi"). In this interview for Q, Tegan explains that when they are in the process of making an album they are only thinking about the songs and writing, not about the business, but they are certainly involved in both. The fact that Tegan and Sara like to take matters into their own hands and be in charge of their music business implies that they want to be perceived as strong independent women who do not need to be managed by men. "Sara sees the need to incorporate more women into the business as going beyond the artists who step 
up onstage to play the crowds. "Ninety per cent of the time we're surrounded by men"” (Lazowski).

\subsubsection{Management}

Due to the ever-evolving music industry, Tegan and Sara have had to make certain changes in terms of management in order to stay on top. They therefore have to be business savvy in order to create music that they are proud of and that fans enjoy (Bendix). In order to continue living off their passion, they need to keep up with the industry trends. "The trend now is to have a long lead-up to your record, play the songs live, have people get excited and finally let them post videos and stuff so we're kind of embracing it" (Tegan qtd. in Bendix). Another change the band has embraced is signing with a record label. During their indie phase, Tegan and Sara self-managed their band and in 2007 they decided to sign with Warner. These decisions left some fans wondering whether the band has lost some of their artistic integrity, while others appreciated the new sound that Tegan and Sara explored once they signed with Warner Brothers (Bendix).

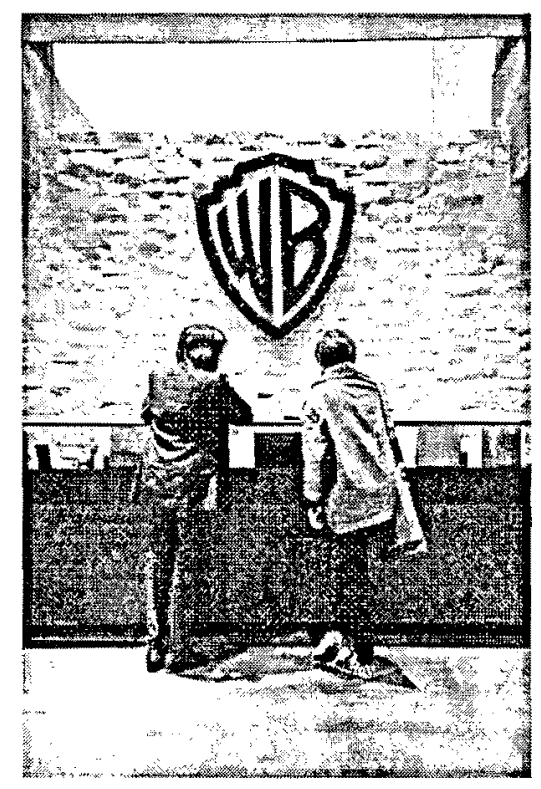

lmage 1 
Initially the artists worried that signing with a label was not the right choice for them because they were an indie band; however, Warner wanted to accommodate the talented artists and offered them three pieces of advice. First, Warner did not want to lose Tegan and Sara and assured them they would figure out a way to work together. They rewrote their deal and Warner was flexible in working under Tegan and Sara's terms. Second, Warner believed that Tegan and Sara had put limits on their success and growth, partially due to their gender and sexuality, and they wanted to help the artists reach their next level of success. Lastly, Warner advised Tegan and Sara to be brave. The record label encouraged them to do something fresh and different, and to stop holding back. The record label motivated them to set their sights and be ambitious ("Music-News.com, Heartthrobs"). According to Tegan, their label acted as a coach during the process, prepping them for greater success. Tegan and Sara tried to persuade their audience that they could never do anything they were not $100 \%$ comfortable with. Consequently, they stayed true to themselves even after signing with a label and going more mainstream. Trusting the advice Warner provided, the sisters sat down and wrote everything they wanted to achieve. They ended up with Heartthrob.

It is important to keep in mind that interviews can also be categorized as part of Goffman's performance theory, therefore we cannot be sure that Tegan and Sara are being genuine in front of the media. Goffman defines performance as "all activity of a given participant on a given occasion which serves to influence in any way any of the other participants" (15). This includes the audience, observers, or co-participants. Furthermore, according to Goffman, "the performer may be engaged in a profitable form of activity that is concealed from his audience and that is incompatible with the view of his activity which he hopes they will obtain" (43). In other words, because Tegan and Sara are in an agreement 
with Warner, it is in their best interest to portray the record label in the best possible light, despite any challenges or uncomfortable encounters they may have had with them.

\subsubsection{Evolution}

In an interview with Sara Quin, Anna Lazowski writes "while Sara acknowledges there has been some evolution since they've been in the business, change can be fairly slow". Tegan and Sara have certainly had to adjust their lifestyle since beginning their career as professional musicians. Throughout the years, they had to teach themselves how to survive in the music industry and what is best for them as a band and as individuals. They had to adjust the way they work and think about their careers. However, there are certainly aspects of Tegan and Sara that have remained the same and habits or traditions they like to maintain. "While some things about the band has changed, some things will always stay the same" (Tegan qtd. in Bendix). For example, Tegan and Sara always play the recorded versions of the songs to start with, but learn other versions of it as well since they often perform in diverse settings. "We learn acoustic, stripped-down versions of each song as well...that's part of Tegan and Sara that will never go away" (Tegan qtd. in Bendix).

Tegan and Sara are finally at a point in their career where they are able to have fun and enjoy themselves. They have worked hard and now have the funds and some time to take a few days off and enjoy their tours more ("Q with Jian Ghomeshi"). "Tegan and Sara are no longer nineteen and riding around the country in a van for most of the year. Not only has their sound evolved, but as people they have grown, which means their priorities have changed" (Bendix). Tegan loves being in the studio and writing, and does not want to be on the road 300 days a year anymore. "We're getting old, it feels like, so our intention with this record [Heartthrob] is to get a bigger audience so that we can sustain ourselves" (Tegan qtd. in 
Bendix). As an indie rock/pop band, they did not sell as many records, and did not get played on the radio; hence, their primary source of income came from touring. To achieve their goal of making a living and not touring constantly, Tegan and Sara decided to become mainstream. "That means having better videos so they get played on television, not just on the Internet" (Tegan qtd. in Bendix). Their objective is to make their band bigger and gain more fans in order to be able to do more, experience more, and have more influence.

Tegan and Sara feel very confident musically ("Q with Jian Ghomeshi"), however, they are constantly learning and improving as musicians and individuals. When Tegan and Sara began writing songs for other artists they applied structure to the process instead of trying unmethodical arrangements as they often do when they write their own music (Bendix). They then decided to apply this structure to their own record making process. Consequently, they believe their new album Heartthrob feels like a "grown up record" (Bendix).

While Tegan and Sara's sexual orientation has remained the same over the thirteen years they have performed together, their approach and presentation of it has evolved. Initially, the two artists were strongly opposed to the media questioning their sexuality or focusing on this aspect of their personal lives rather than their music. However, as time passed, it appeared as though the media, the fans, and Tegan and Sara shifted their attention in the opposite direction. While the public reduced their interest in the musicians' sexuality, Tegan and Sara finally felt comfortable enough opening up about it.

\subsection{WHO ARE TEGAN AND SARA?}

Tegan and Sara spend over 200 days of the year on the road together, so they have a lot of bonding time ("On the Hour ( $\mathrm{CBC}$ )"). Although the sisters have been accomplishing their goals as a musical force together, they do not live in the same city. Tegan lives in Vancouver, 
and Sara has settled in Montreal. While this geographic distance has created some challenges in terms of distributing responsibilities, the separation has allowed each of them to develop their own style and strengthen their individuality ("On The Hour ( $\mathrm{CBC}$ )"). "Both driven to create, they work independently on various side projects, continuing to evolve as artists" (Lazowski). Tegan and Sara's mutual friend, Krista, believes that "talking about them as a "they" is not fair. They are different people - completely different people sometimes" (Get Along). Consequently, I think it is only fair to briefly examine Tegan and Sara's identities separately, especially since they often write music for their band independently.

After a phone interview with Sara, Lazowski concluded that she is candid, self-reflective and seems to understand her own actions and motivations, although her desire to be open and connected does have its limits. Sara admits to being fascinated, even obsessed with intimacy and connections, but says she really isn't as wrapped up in turmoil as one might expect from listening to her music (Lazowski). "When I step outside my songs, I always find my situations are less dire than they seem. You can't tell much about me as a person on a detailed level, but at the core of the music you can tell how sensitive Tegan and I are in our lives" (Lazowski). Sara describes herself as a patient, pre-meditated individual. She likes to self-evaluate. Consequently, when it comes to writing music, Sara carefully examines herself and her relationships.

Tegan, on the other hand, is more of an extrovert. Sara describes Tegan as confident, impulsive, risk-taking, and believes that this is reflected in her song writing. Tegan is also the one who makes most of the business decisions ("Interview with Tegan and Sara: Origins and Influences"). For two individuals, who present themselves as relatively reserved and wish for the focus to be on their music, Tegan and Sara do not seem to mind talking about who they are 
as individuals. By observing their mannerisms on camera, one can recognize Sara's patient and quiet nature, and Tegan's spontaneity. Their fashion style over the years has reflected their musical sensibilities. During their indie phase, Tegan and Sara dressed in a deliberately unpolished style, wearing looser clothing and messy bed-head hair. Today, they dress in more carefully assembled colourful outfits, reminiscent of the $90 \mathrm{~s}$, which is reflective of their new pop sound. It is important to question both Tegan and Sara's camera presence however, as we cannot know for sure if this reflects their identity off camera. "Sometimes the individual will act in a thoroughly calculating manner, expressing himself in a given way solely in order to give the kind of impression to others that is likely to evoke from them a specific response he is concerned to obtain" (Goffman 6). Other times, as Goffman points out, an individual will be calculating in his/her activity but unaware of it.

\subsubsection{Tensions with Media}

It wasn't until we released our second record that people started to enquire about our lives outside of music and there was this moment when I was like, geez, everyone keeps asking us about our boyfriends and like what we do? The president of our record label at the time was like, "Well are you gay?" And we were like "Yeah," so he was like, "Well, just say that you're gay." And so we just did it. (Tegan qtd. in Schwartz)

"Sara acknowledges that there is a desire to start pushing the boundaries of the Tegan and Sara identity" (Lazowski). While both women are openly lesbian, they do not believe their music has a sexuality. Both Tegan and Sara wish the press would stop fixating on their sexuality. Their goal is to make music for everyone and they want everyone to focus solely on their music. "Tegan and Sara hope their new album [So Jealous], makes people focus on their 
sound rather than the whole "lesbian Canadian twin" thing" (Marcus 58). While it is clear that they do not want their personal identities and the public's fetishization of their twinness/gay-ness/Canadian-ness to overshadow their music, this desire for their identity to be dissociated from their music could be interpreted negatively by their fans and the queer community. After thirteen years of being together and sharing their music, Tegan and Sara finally feel as though fans and the media are focusing on their music and not only on their personal lives. Interestingly enough, now that the pressure is off, they feel more comfortable deconstructing their relationship publicly.

\subsubsection{Relationship with Fans}

It is important to acknowledge that while some social media is controlled by Tegan and Sara, such as their personal Twitter accounts, other sites are controlled by their label, Warner Bros. Records. Furthermore, there is social media devoted to Tegan and Sara created by their fans. This means that the two musicians are not in control of a lot of media that is related to their public identity. For this reason, this paper primarily focuses on interviews and videos that Tegan and Sara are either presented or quoted in.

Tegan and Sara are driven to build and maintain a very strong connection with their fans (Lazowski). "They use Twitter, post blogs, release books and maintain a strong Web presence with audio, videos and enough merchandise options for even the most avid fan" (Lazowski). The artists use Facebook to inform fans about their upcoming tours and appearances, album releases, and recently released interviews and music videos; however, this page also allows fans to leave comments, view photos, take surveys, and indirectly interact with Tegan and Sara. With 796,626 likes this is a great tool for the band to reveal aspects of their public identity, and find out what their fans are after. While it promotes the artists and their albums, 
it also shows Tegan and Sara's interaction with their audience, allowing fans to tag themselves in photos with the musicians. With hundreds of photographs the sisters have posted of them with fans at various events, the time and effort they put in to meet with their fans seems undeniable. Tegan and Sara also have 278,545 followers on Twitter, and numerous gifs, videos, photographs on Tumblr.
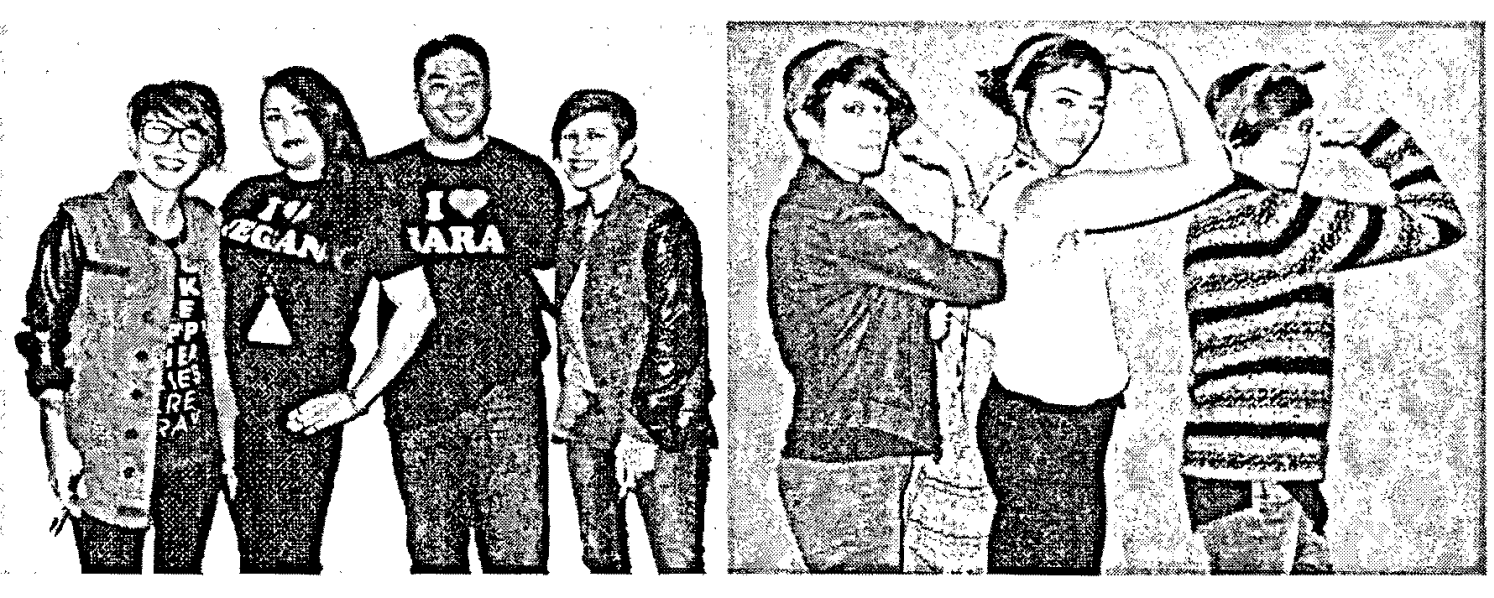

Image 2

The photograph on the right is meant to resemble the famous "We Can Do It" poster of a woman in a blue-collar work shirt promoting feminism. With this photo, the fan, Tegan, and Sara, are trying to show female empowerment and therefore embracing their sex and sexuality.

During live shows, Tegan and Sara are very personable with their audience. During their first professional gig, while they were still in high school, the organizers informed Tegan and Sara that they needed to play for thirty-five minutes ("Music-News.com, Heartthrobs"). Unfortunately, they did not have thirty-five minutes of music at that point, so they improvised by making conversation with their audience in between songs. For a pair that describes themselves as socially awkward, they certainly did not seem to have a problem connecting 
with their audience, even in the beginning. They quickly developed a rapport with the crowd and created a relationship between themselves on stage and with their listeners. If there were ever moments of awkwardness, they were taken to be intentional and comedic by the audience. Tegan and Sara continued this habit of making jokes or conversation during their performances and are still quite personable with their fans during live shows.

When they first started playing together professionally, Tegan and Sara acquired a lot of queer fans, a community that would follow them only to gain advice and look up to them because they are gay, not necessarily because they liked their music ("Music-News.com, Heartthrobs"). Now that they have expanded their genre and gained more experience they are able to advise on such topics, and their audience has also evolved and expanded to include all kinds of people. "Our audience is much more mixed than it used to be," says Tegan. "A huge part has gotten really young, and regular straight-looking hoochie types with their boyfriends are getting down to "You Wouldn't Like Me"" (Sara qtd. in Lazowski). Musicians and fans frequently evolve; however, they will not always, or even often, evolve together and in the same way. "It's natural that you lose fans along the way," Tegan admits ("Tegan and Sara Quin in Studio Q").

With the evolution and expansion of Tegan and Sara's music, their fans have also evolved and expanded. Sara believes that if they stayed the same and fans knew what to expect of them, they would lose more fans. She wants to be able to challenge herself and do as much as a performer as she can. Together, they want to surprise their fans and always be gaining new ones. "I think our audience sometimes, especially our diehards, gravitate to the more complicated music, but ultimately when we're playing the record live people seem to gravitate toward the more classic, traditional arrangements so we tried that a lot more" 
(Tegan qtd. in Bendix). Because the two artists often write their music individually, they've come to realize that a different type of fan is drawn to Sara's songs than to Tegan's. Sara finds that the fans drawn to her songs are those who are a little embarrassed by emotion and don't like to express their feelings. Those who like Tegan's songs are the fans in the front row crying ("Quin in Studio Q"). Tegan and Sara seem to understand and relate to their fans on an intimate level. "We see them crying and screaming and we get it" (Get Along). Sara recalls standing in line with Tegan for hours, waiting to purchase The Smashing Pumpkins tickets and at the end of the show sitting there holding each other, crying. In my opinion, because Tegan and Sara believe to personify devoted fans, they are better able to appreciate and understand the fans they have.

Their latest record Heartthrob truly shows Tegan and Sara's differences. Tegan writes about nostalgia and teenage love and lust, while Sara writes about the complexities of more recent relationship with little subtleness. Sara argues that they have flipped roles on this record. Her songs will have people screaming along and being more intense while Tegan's songs are more chilled out this time. At the same time, Sara reminds the interviewer and those listening that their duality is what their band is all about and what makes up Tegan and Sara ("Quin in Studio Q"). 


\section{Chapter III: CASE STUDY ANALYSIS OF MUSIC VIDEOS}

\section{1 "THE FIRST" (2000)}

Tegan and Sara's first two records were more acoustic based. People called their sound 'folkier' and both albums had a more organic sound ("Music-News.com, Heartthrobs"). "The First" is from Tegan and Sara's second album, This Business of Art, released in 1999. This indie rock song was written by Tegan but both singers' voices are layered throughout. It has a dominant acoustic sound and upon a first listen, it sounded somewhat harsh, boyish and angry. The vocal texture is aggressive, deep, and the pitch is quite low, staying at that level throughout. The snare drum has an industrial tone and the structure of the song is quite complex. The first verse begins with Tegan singing, then Sara comes in half way through, and then the drums are introduced. For me, this song does not seem to have a clear structure and it was challenging assigning the chorus. While there is a hip-hop influence and Tegan sounds as though she is rapping, the song also has a 90 s vibe and could be part of the "riot grrrl" genre. Riot grrrl is related to the punk rock scene that was dedicated to expressing radical feminism (Rundle). The layered guitar and deep ominous sound of "The First" also resembles the Smashing Pumpkins and Hole, Tegan and Sara's influences.

\subsubsection{Lyrical Analysis/Meaning}

Tegan and Sara's first words in "The First" music video convey their frustration with gender role expectations and how people respond to their sexuality: "Sean this is kind of a boy set, did you know we were girls?" Tegan complains at the beginning of the music video, before the song even begins. "Yeah where's all the flowers and sh"t?" Sara adds and everyone laughs. 
Tegan and Sara's clothes, hair, positions, whether intentional or not, all make a statement about who they are and how they want to be perceived. Music videos are a product, and Goffman reminds us that,

in those interactions where the individual presents a product to others, he[/she] will tend to show them only the end product, and they will be led into judging him[/her] on the basis of something that has been finished, polished, and packaged. (44)

The end result of this carefully constructed music video does not offer any props that may associate Tegan and Sara with being overly feminine - in fact it is almost overtly masculine, or at least gender neutral. By including their sarcastic complaints at the beginning of the video, they are trying to convey their frustration with the stereotypical assumptions that just because they are female people may expect them and their video to incorporate typical feminized attire and props. Another explanation for having this footage as part of the final product could be because it reveals the band members as female, which may not be clear to the audience.

The lyrics that make up "The First" are complex and have a toughness to them. Tegan does not write or sing about romance or love, but about the hardships of life.

They go from kindergarten to killing sprees

They go from heartache to inner peace

100 foot ceilings 100 percent deceit

He said let's leave this between you and me

My cats watch my stuff leave my house

Between you and me the cat burglars are 
What did you see what did you steal. (Tegan and Sara "The First")

Referring to Richard Middleton's three ways in which lyrics can be shaped to music, (story, affect, and gesture), it is clear that in this case the words act as a narrative, governing the rhythmic/harmonic flow. Tegan and Sara's voices tend towards speech. They do not merge with the melody and are not absorbed into the music. We cannot be certain as to what Tegan had in mind when writing the lyrics to this song, however "it is certainly clear that words about music - not only analytic description but also critical response, journalistic commentary and even casual conversation - affect its meaning" (Middleton 220-1). After describing the musical component of the song, then reading fans' comments to what they felt this song is about, my interpretation of it began to change. Whereas 1 understood it to be an angry song, other fans believed it is about seizing the day and celebrating life.

Simon Frith does not believe that an analysis of the lyrics alone can tell us much about the musicians. "Pop songs celebrate not the articulate but the inarticulate, and the evaluation of pop singers depends not on words but on sounds - on the noises around the words" (Sound Effects 35). Similarly, Vernallis argues that "each medium in music video - image, lyrics, and music - is deficient in itself' (94). If one were to watch a muted video, the image may seem naked and the viewer may have a difficult time understanding the visual narrative. Music gives lyrics a certain tone and feeling; however, sound alone can offer endless interpretation. Each individual medium seems to influence the overall experience - creating a sum that is greater than its parts - and for Vernallis, each medium "can be said to define the others" (94). Therefore, it is not possible to understand the artists based on the song alone. It is important to take into consideration the music video as well, in order to come to a conclusion regarding their public identity. 


\subsection{2 "The First" Music Video}

"The First" music video was directed by Sean Turrell in 2000. This music video primarily falls under the "pseudo-documentary" genre of music video. Although the video does not explicitly reveal the everyday working life of these professional musicians, it can be interpreted as a visual representation of their rehearsal time or as an intimate performance. The music video takes the viewer into Tegan and Sara's "rehearsal studio", portraying them as skilled, professional musicians. There are also frequent close-ups of them playing guitars and singing, another feature of the "pseudo-documentary" music video. However, "The First" music video could also belong to the "staged performance" genre, as the performance seems to have been specifically designed for the video. A camera crew is present at the beginning and end, and the director uses a clapperboard to mark the particular take recorded during production. Tegan and Sara address the camera, another characteristic of the "staged performance" music video, and the music video strives to highlight the talent and image of the artists, rather than reflect the narrative of the lyrics or the tone of the music.

\section{Setting}

In examining the setting of this music video, I will draw from Vernallis' five basic types of place in music videos. The setting of "The First" music video belongs to the third category, a schematic representation of a familiar type of site, for example, a couch in a warehouse to suggest a living room. It is difficult to tell whether this video was filmed in someone's living room or a warehouse converted into a space suggesting a living room. There is also a small possibility that this space has specific acoustical properties and therefore could also be an extension of their recording studio. 
Based on the low production quality of the video, it is quite obvious that this is one of the first videos Tegan and Sara have produced as it looks unpolished. It is set in a typical musical environment, one that resembles a rehearsal space in an old house. Later in the video we see the two performers walking down a street and under a bridge, making use of the environment they have to work with. As they walk through the streets, singing "We decide to go out walking / The whole time that you're talking..." images of a metallic bridge, paved road, and black and white traffic signs flash in between shots of Tegan and Sara. Although the overall production and quality of the video is not as sophisticated as their latest videos, it does reflect the grungy, authentic feel of the song.

The video begins with Tegan and Sara sitting in a room with a rectangular carpet on the floor, a brown couch and the two stools they are sitting on. The room also contains speakers, amplifiers and a drum-set; however, the drums are not played by anyone at any point during the video. With the statement made at the beginning of this video, "Sean this is kind of a boy set," Tegan and Sara suggest that there is a difference between a boy and girl set, and theirs resembles the former. Consequently, this means that their definition of a "boy set" means having few or no props other than their instruments, a couple of stools to sit on, and a couch. It is definitely not a flashy set. With this intended "boy set" Tegan and Sara are making sure they are not mistaken for feminine individuals. They create an asexual mood and set. However, this effort to stay away from any gender role expectations may have the opposite effect on some viewers and bring their sexuality to the audience's attention instead.

\section{Body/Gestures/Expressions}

Simon Frith's theory that a musician's body is also an instrument will be connected to the analysis of Tegan and Sara's bodies in their music videos. While there is very little 
movement in "The First" music video, the two musicians appear to conform to their musical instruments. Tegan and Sara are primarily seated on a stool, each playing guitars, which happen to cover up their chests, either deliberately or unintentionally. If we apply Frith's argument to Tegan and Sara's position and body movement, it is possible that the reason they are sitting is to make it easier for them to play their guitars. They are adapting their bodies to their instrument. Their slouched, aloof body language seems to be catering to their "indie" sound and look. It is rare to see female musicians with such apathetic attitudes. One can distinguish between their personalities by looking at their body language and seating position. While both Tegan and Sara are seated on the same type of stool, Sara's knees are touching and her torso is slightly curled towards her guitar, conveying a quieter, shy demeanor. She looks delicate and soft-spoken. Tegan on the other hand, sits with her left leg slightly higher than her right (perhaps a more boyish and self-assured position), and her upper body seems stronger, exuding a more confident and outspoken individual.

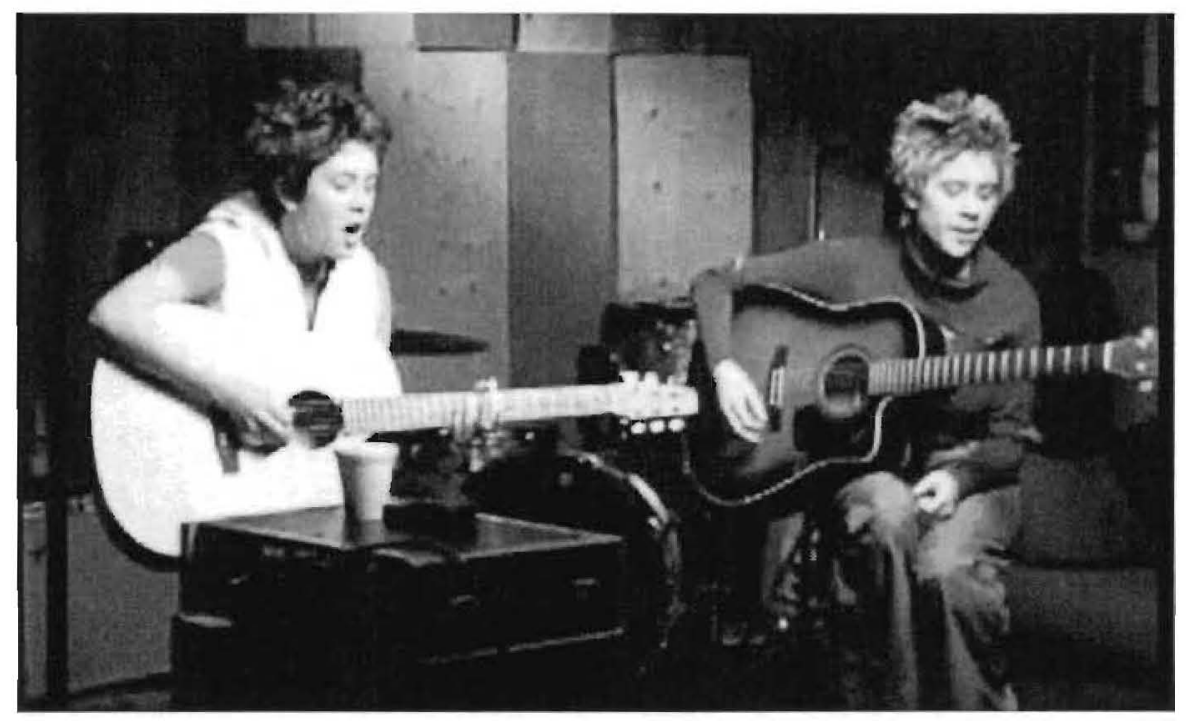

Image 3 
The expressions on their faces, especially Tegan's, are worth noting. Both Tegan and Sara frequently sing with their eyes closed in this video; however, Tegan's facial expressions are more intense than Sara's. She contorts her mouth emphasizing the shape of the words and squints to emit a passionate performance. Sara's expressions are more subtle, perhaps because of her quieter nature or the fact that she is accompanying Tegan with the harmony and does not want to take away from her presence.

Style

Tegan and Sara are both barefoot in this music video, something that is highlighted in the first scene, by them sticking their legs out directly in front of the camera. Their attire is very simple and resembles comfortable, loose fitting camping wear. They are both wearing loose pants, Tegan black and Sara brown, with fleece tops. Tegan has a bright orange tee shirt underneath her white hooded vest and Sara is wearing a simple blue zip-up sweater. Both Tegan and Sara's hairstyles have a similar shaggy look to them. Sara has highlights as well. Tegan has a piercing below her lip and several earrings in her right ear. Their makeup is simple and natural looking. Their overall look gives off a grunge/indie/"wasted youth" vibe. Their attire does not highlight their bodies and it is difficult to make out their figures.

\section{Aesthetics}

"The First" music video begins and ends with four viewpoints displayed at one time. While the four perspectives keep changing during the first twenty seconds of the music video, at least one of the viewpoints is always of Tegan and Sara sitting on their stools getting ready to perform. The viewer also sees the camera crew setting up, the director holding the clapper, and a clockwise view of the entire set, including the lighting behind the crew. This revelation 
of the set and a peak at the making of "The First" music video gives off a casual, run-down feel to the production and video.

"Color speaks immediately to our emotions and has such an intense effect on us" (Seward Barry 264). The ambience of "The First" music video has an earthy tone. The walls of the room are wooden, and brown, beige, yellow and black hues caught my eye most frequently. There is also a green door, and a burgundy coat on a brown couch giving off an organic feel. When Tegan and Sara go for a walk outside, it appears to be fall and we see autumn coloured leaves, trees, a grey sidewalk and grey-blue bridge. Everything seems to have a green/blue hue to it. Vernallis argues that, "a video that stays within a restricted color

scheme maintains visual consistency as well as uniformity of mood" (127). Green and blue are meant to calm the viewer but can also connote grief. The mood of this music video is definitely consistent for me. It has a gloomy feel, reminiscent of grey days.

\subsubsection{Creative Control}

As independent artists, Tegan and Sara managed their own sound and image. While Sean Turrell is listed as the director of "The First" music video, there are no resources on his production of this music video or collaboration with Tegan and Sara. I believe that Tegan and Sara had a lot of creative control at this time.

\subsection{4 "The First" Summary}

Looking at "The First" sound, lyrics, and music video together, it is clear that Tegan and Sara are trying to conceal their sexuality at this point in their careers. In a recent interview with Duncan Cooper, Tegan and Sara reflect on their past and admit that they have been aware of the fact that they wanted to prove that they were a band. "This of course, no man would ever have to prove. But we have felt like we have had to prove it so there was a concern 
or a nervousness around playing up our image too much" (Cooper). Consequently, they decided to down play any femininity, and in order to gain a large fan base and be respected musicians, their video became about the action of performing. In "The First" music video, Tegan and Sara attempt to demonstrate that they are professional musicians by having the camera primarily focusing on their interaction with their instruments. This highlights their technical skills. Furthermore, their attire and demeanor fit the masculine encoded female stereotype. "To Goffman, our gendered behaviour, as well as our concepts of masculinity and femininity, are scripts that are dictated by our environment that we consciously and unconsciously learn and perform in order to play our appropriate roles in society" (Wallis 161). During the time this music video was produced and released, society often associated women with short hair, visible tattoos, and piercings as automatically lesbian. So while Tegan and Sara tried to present themselves as more masculine or gender neutral and have the viewer focus on their music and instruments rather than their gender, they inadvertently gave the audience reasons to ask questions about their sexuality.

\section{2 "BACK IN YOUR HEAD" (2007)}

"Back In Your Head" is from Tegan and Sara's album The Con, released in 2007. Tegan describes the songs on the album as sad and devastating. "Sara and l always say we've written some of our best music, no doubt, when we're sad. When I was sad and writing The Con, pretty much everything I wrote made it on the record. I was like, I'm devastated, here's my devastation in musical form" (Tegan qtd. in Greene 2). The high pitch and upbeat sound of "Back In Your Head" however, does not make it sound like a sad song. Compared to "The First" this song has a much happier vibe. The rhythm and lyrics of the song are much simpler than "The First", with a basic ABAB structure. 
Tegan and Sara take a break from their guitars, and bring in the piano and drums. While the instruments give it a poppy upbeat sound, this song is about relationships and the distance created between a couple. "Back In Your Head" not only contains one of the hugest hooks in the band's entire discography, but also might be one of the best breakup songs of all time, a song full of tension with a recurring earworm of a chorus" (Pelly).

\subsubsection{Lyrical Analysis/Meaning}

It is not as simple to label the lyrics for "Back In Your Head" as expressive objects, narrative, or acting like sounds, as it was for "The First". The same way Railton and Watson's music video genres can overlap within one song, so too can Middleton's three lyrical adaptations. While the words for "Back In Your Head" can function as expressive objects, merging with the melody at times and generating feeling, the lyrics and instruments are also separate during the chorus. As Sara sings "I just want back in your head", the music accompanying her voice is subtle and distant, placing emphasis on the lyrics. The music then mimics the words after they have been sung. Consequently, it can be said that at this point in the song, the words acts like sounds and her voice becomes an instrument. This musical accompaniment and the repetitive nature of the song brings more emphasis to the lyrics, but at the same time, it embeds the catchy rhythm into the listener's mind and body, leaving them singing or humming the tune for the rest of their day.

As with most Tegan and Sara songs, this one draws from intimate experiences and reflects their past relationships. Sara describes the song as a stream of consciousness. While she was still in a relationship with someone, she started to emotionally connect with someone else ("Tegan \& Sara - About BIYH"). The first words she wrote for this song are "I'm not unfaithful but I'll stray", meaning she would not physically cheat on her partner, but was 
interested in someone else emotionally. The lyrics, "Build a wall of books / Between us in our bed" could mean their relationship had turned into reading book after book before bed, and no longer having a physical connection. "Repeat repeat the words that I know we both have said", may refer to the couple saying "I love you" out of habit, and not meaning it. "Remember when I was so strange and likeable", reminiscing about the beginning of a relationship usually means the end is near. These lyrics and Sara's description writing the song all confirm that it revolves around a physical and emotional relationship. "The words of a song give us the key to the human universe that the song inhabits" (Liang qtd. in Middleton 228).

\subsection{2 "Back In Your Head" Music Video}

The music video for "Back In Your Head" was directed by Jamie Travis. The video was released in 2007. From the very first scene, one is able to classify this music video as part of the "staged performance" genre. The red curtains open and on stage are Sara, (playing the piano), and Tegan, (the drums). As Sara begins singing the lyrics to "Back In Your Head" she immediately addresses the camera. Unlike "The First" music video, which primarily focused on the musicians, their hands and their interaction with their instruments, "Back In Your Head" is more about the audience. The auditorium is filled with individuals dressed in white, swaying their heads to the rhythm of the song, while a single person dressed in black sits perfectly still amongst them. This image could be a visual metaphor for individuality. The visual and lyrical narratives, although different from one another, are both complex and intriguing. There is a deeper meaning to the lyrics that the listener must interpret for themselves, and perhaps a visual metaphor can be found in the video, but it is difficult to offer a general analysis of either. 


\section{Setting}

Tegan and Sara appear to be performing in a school auditorium on a wooden stage, on which two naked statues are situated in the left and right front corners. Their backdrop consists of blue and green curtains and balloons weighed to the floor. The walls of the auditorium are white and the numbers $1,2,3,4$, or 12 and 34 are visible on the back wall. The chairs the audience is sitting on are light brown. Approximately 120 individuals sit in the middle row, 75 in the left section, and 75 in the right section, making it a total of about 270 individuals, 269 of which are dressed in white and 1 in black. This video seems to focus more on the audience Tegan and Sara are performing for, rather than just the two of them and their technical skills.

At 1:34 the setting changes and the individual dressed in black is walking through a factory. The mood and setting make it seem as though he should not be there. Everyone else, dressed in white, seems to belong in this environment, but no one pays attention to the black figure. He approaches a valve and as he turns it clockwise, balloons start falling onto the stage Tegan and Sara are singing and playing on. There are a few distant shots throughout, emphasizing the theatrics of Tegan and Sara performing on a stage as professional musicians. This reiterates their statement about wanting to be taken seriously and prove themselves as artists, however, there are definitely fewer shots of Tegan and Sara interacting with their instruments than there were in the previously discussed video.

\section{Body/Gestures/Expressions}

Movement is initially created by the seated audience, swaying their heads left and right, thereby placing emphasis on the audience. At 2:17 when Sara sings "Run run run..." her and Tegan both start running off the stage and down the stairs through a factory. The camera 
captures them from the waist up as they are running, creating a more sexual and feminine image. Their facial expressions often convey fear, doubt, and uncertainty. As Sura sings "When I get a little scared", she and Tegan actually look scared. They frequently look to each other as if engaging in telepathic conversation, therefore acting as one unit.

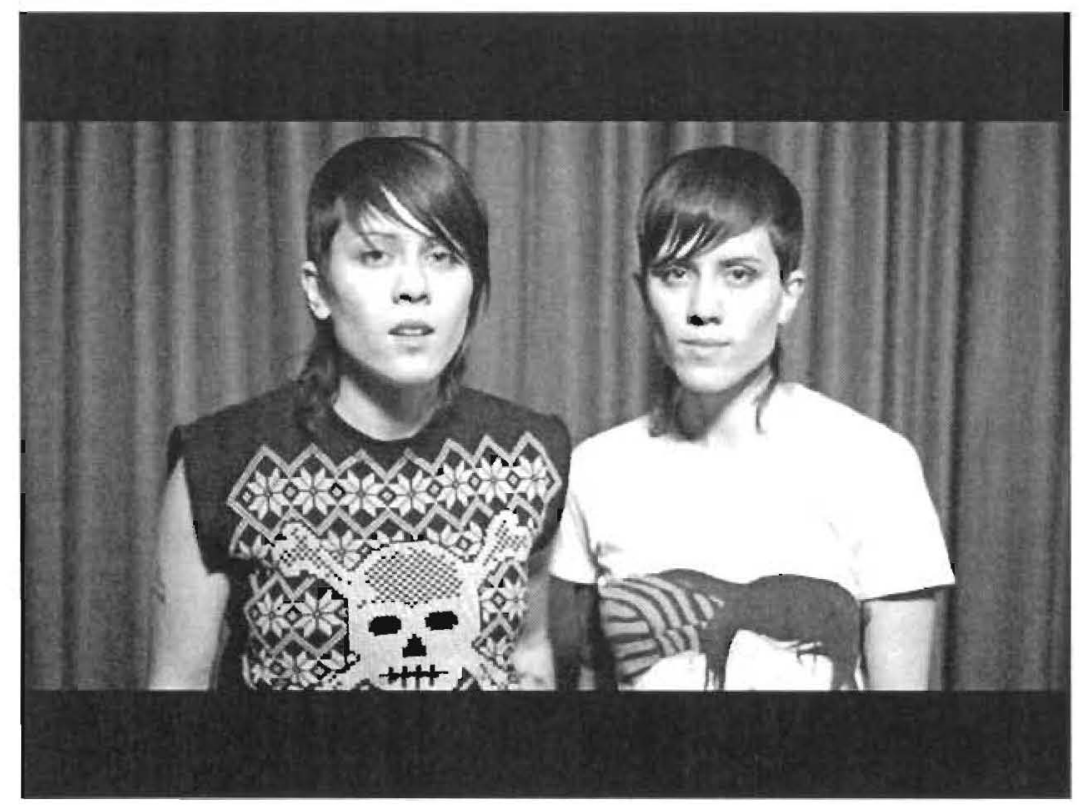

Image 4

\section{Style}

Tegan is wearing jeans and a black sleeveless shirt with a large white skull on it, while Sara wears black pants and a white tee shirt with a female face on it, somewhat resembling Tegan and Sara (see Image 4). Perhaps they purposefully wore opposite colors of tops to match the opposing black and white suited figures. In comparison to "The First" video where they wore loose, long-sleeved shirts and baggy pants, Tegan and Sara look a lot more feminine in this video. Their tops and bottoms are tighter and they are showing some skin. Their hairstyles are similar to each other's and more feminized, as they both have fem-mullets with slicked side bangs. It is more obvious that they are wearing make-up, and even though some 
of their piercings and tattoos are still visible, they look more discreet. They also look much more mature and image conscious.

\section{Aesthetics}

The camera work is interesting in that it abruptly shifts from face to instrument in some occasions. For instance, when Tegan is playing the drums, the camera moves from her face to her hands along with the beat of the drums numerous times. The visual experience seems significant in this music video, as various colours, lights, and movements are incorporated, making it part of the "art" music video genre. It is clear that a greater production took place and that this video was produced on a higher budget than "The First".

The large, seated audience Tegan and Sara perform in front of, is initially dressed in white body suits, that cover everything but their eyes and mouth. There is one individual dressed in a black body suit sitting in the middle row. Suddenly the rest of the audience creates symmetrical colour patterns as two columns of the audience appears in red suits coming close together until they are side by side, then further apart. The two red columns turns into four, again moving away and toward each other, accordingly with the music. The colours used, and the formation of the three columns resembles a Canadian flag, and since the video appears to be about individuality, perhaps it is reflective of Tegan and Sara's Canadian identity. 


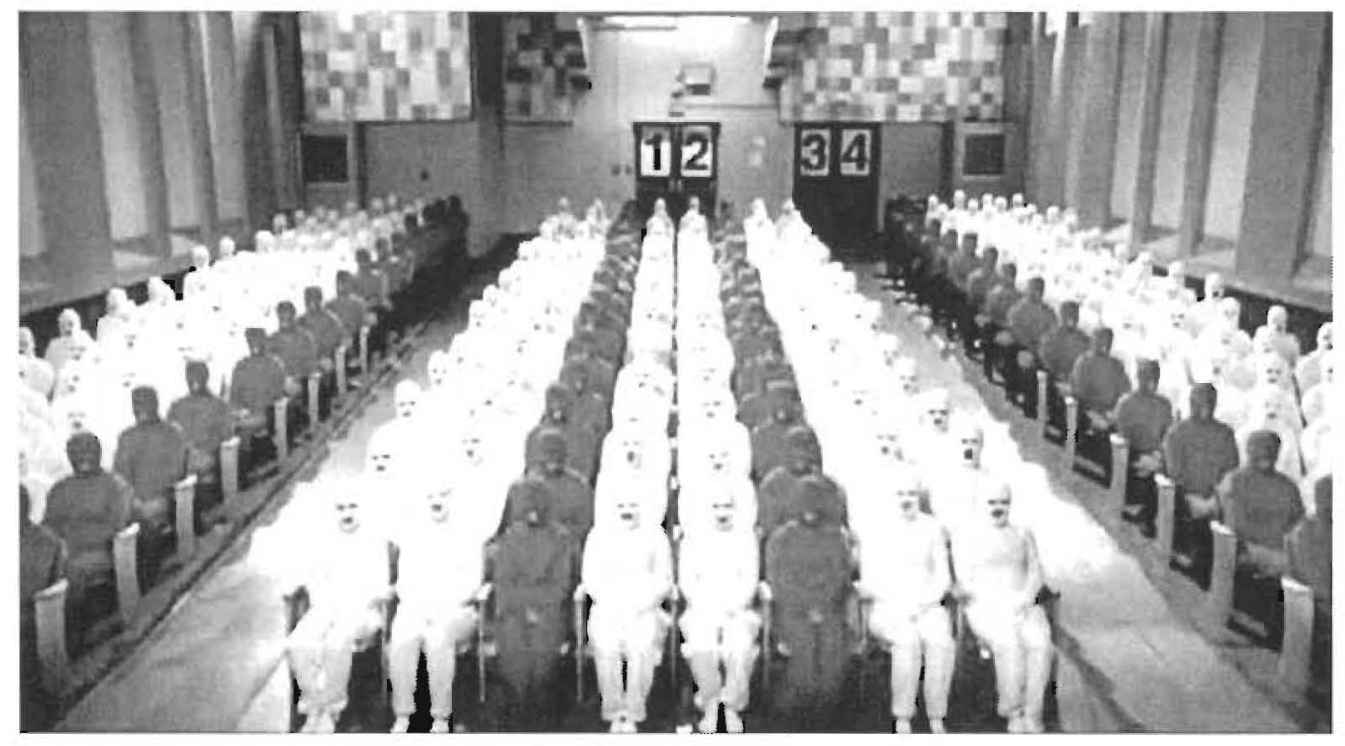

Inage 5

At 1:53, the first three rows of the middle column consist of people dressed in red suits.

The group of red moves up the middle column to the rhythm of piano, then back down, this time split in half, so that one square of twelve is diagonally above the other. The entire visual experience is quite mesmerizing and perhaps intended to captivate the viewer/listener to want to be part of the experience. White, red and black are strong colours that could respectively signify purity, passion, and darkness or evil. However, because the video does not correlate with the lyrics, it is challenging for a viewer to make sense of it.

\subsubsection{Creative Contribution}

Jamie Travis is a Toronto-based filmmaker, who has written and directed awardwinning short films, music videos and television commercials (Klinger). He has directed the music videos for Tegan and Sara's songs "Hell" and "Back In Your Head". This can mean that the artists trust him, and appreciate his style and visual representation of them. In an interview for blogTo, Travis writes:

Tegan and Sara have given me loads of control over the videos I have directed for 
them, especially for "Hell" but also for "Back In Your Head". I love working with a fixed starting point - in this case, a song. The girls tend not to want videos that explain their lyrics in a literal way, so I am left to explore tone and flights of fancy. (Simard)

As I predicted, Travis confirms that this particular music video does not attempt to dramatize the lyrics. However, it does reflect the tone of the song, and after examining Tegan and Sara's style within the video, I believe it also embodies their public identity at the time.

\subsection{4 "Back In Your Head" Summary}

This song's more high-pitched sound and the intimacy of the lyrics, illustrates a great shift in sound since Tegan and Sara's "The First". "Back In Your Head" emphasizes their gender and invites the listener to fill in the blanks regarding Sara's intimate experiences. On numerous occasions, both artists have explicitly described how they draw from past experiences and relationships to write their songs. Sara has even addressed this specific song and admitted to the content of it being about her past relationship. Consequently, it is impossible for fans and the media to ignore these facts and leave them alone. Curiosity is a part of human nature, and it is natural that listeners would want to know with whom she was in a relationship with at the time, why they broke up, if she is single now, etc. Tegan and Sara seem to be teasing their audience with their music and unrealistically expecting them not to focus on their gender and sexuality.

While the music video for "Back In Your Head" does not complement the lyrics, there are displays of femininity and sexuality in it as well. For instance, the naked statues on stage, their fitted clothing, the close-ups of their faces with make-up on, them running through a steamy factory, all highlight Tegan and Sara's new image and take the focus away from them merely 
being professional musicians. Rather than just sitting in a room playing their guitars with their eyes closed for approximately three minutes, this video involves movement, reveals more of their bodies, and displays looks of concern and innocence on their faces as if they seem unsure of what is going to happen. In the media, "Goffman concluded that overall women were presented as precious or fragile, passive, submissive, and in need of the protection or goodwill of others" (Goffman qtd. in Wallis 162), and that is how Tegan and Sara seem to be portrayed in this video. They are no longer trying to conceal their sexuality, and seem to be on their way to embracing the stereotypes they initially tried to oppose or ignore.

\section{3 "CLOSER" (2012)}

Tegan and Sara are well-rounded people and have had both successful and failed relationships. Most of their previous albums have focused on their break-ups rather than the happy moments. "Even when I'm happy I find it much more interesting to talk about when things have gone wrong," Sara admits ("Music-News.com Heartthrobs"). With their latest record, Heartthrob, however, Tegan and Sara are trying to break away from that habit and keep the sound and material up-beat. With this new record and their new single "Closer" Tegan and Sara wanted to try something different and keep their audience excited and challenged. They too express the need to be challenged and excited with each new album and song. Tegan and Sara believe that the first song released off an album is most representative of that album. They knew "Closer" was the right choice in this case.

Tegan has always been fascinated with her memories and the past, and while writing "Closer" she explains that she was thinking back in time when she wrote it. This is a nostalgic song that goes back to her high school days. It seems that the structure of Tegan and Sara's songs has become more obvious with time. "Closer" has a clear ABAB structure, and a very $90 \mathrm{~s}$ 
pop sound. "With pop songs, music is most commonly composed first and the lyrics second" (Vernallis 138). However, while writing "Closer" Tegan started singing almost immediately and decided not to play it on guitar. After spending a long time writing a different song, (which did not make the record), she decided to write a song the old-fashioned way, threw down three chords and started singing (Bendix). The song is composed of the classic "versechorus-verse-chorus-bridge-chorus," a structure Tegan believes translates easier and is more accessible for fans.

\subsubsection{Lyrical Analysis/Meaning}

Eventually Tegan and Sara started incorporating keyboards, instead of piano and guitar in their music. They began using their vocals together to create interplay. Their goal was to turn their vocals into instruments ("Music-News.com Heartthrobs"). It is clear that in "Closer" the words act like sounds. The music absorbs the words that function as musical effects and rhymes. For instance, Tegan sings the word "closer" in such a way that it blends with the sound of the synthesizer. Her voice becomes an instrument.

In talking about the Heartthrob album, Sara describes how "there's something embarrassingly raw about some of [the] lyrics, but it also feels good to admit things and release it" ("Quin in Studio Q"). While Tegan reminisced about her past relationships in hopes of writing "Closer", the duo decided they did not want to write songs similar to what they had already written, such as some of their self-deprecating, and self-loathing songs. "I still want to write about love and relationships, but you know what l've never written?" Tegan asks Andy Greene during their interview, "A love song. An infatuation song. A sexual song," she continues before he could guess. "I just wanted to write about wanting to get it on with somebody. Like 'Let's get it on. Let's get closer. Lets' do this. Let's get to know each other.' That's what came 
out of me in like twenty minutes and the song was done" (Bendix). Because women are often stereotyped for wanting relationships and men for wanting sex, Tegan and Sara continue in their attempt to break down these stereotypical gender walls and do the opposite, the unexpected, however with this song, instead of ignoring their sexuality they confront it head on. Writing this song helped Tegan gain a newfound clarity about who she was and what was motivating her. "It's about the eternal journey, the innocent, youthful summer love..." (Bendix). Tegan believes that "Closer" will resonate with people in their age group ("Quin in Studio Q").

\subsection{2 "Closer" Music Video}

The music video for "Closer" was directed by Isaac Rentz in 2012. Using Railton and Watson's model, this music video is a combination of the "art" and "narrative" music video genres. On the one hand it is about the visual experience. Various colours, movements and lights are utilized. It is definitely a promotional video as it clearly displays the name of the artist and song on the TV screen at the beginning of the video. At the same time, this music video tells a story. It illustrates the lyrical content but also goes beyond it to epitomize Tegan's nostalgic feelings about her past relationships and heartthrobs. "It was time to shake things up" Tegan told SPIN. With this in mind, Tegan and Sara's 90s inspired music video for "Closer" became fun, flirty, poppy, with numerous make-out sessions and karaoke re-enactment in "their" living room. It is clear that Tegan and Sara's budget has increased and a lot more production went into the making of this video than the previously examine videos, especially "The lirst". 


\section{Setting}

The living room this music video is set in contains colourful helium-filled balloons resting on the ceiling, creating a party-like atmosphere. Parts of the video are filmed in what appears to be a bedroom, where opposite and same-sex couples playfully fight, paint each other's faces, kiss, and tease one another on a bed. There is a fort in the living room made up of silky sheets and white feather pillows. A few of the men and women are playing spin the bottle, bringing the viewer back to the 90 s, and placing emphasis on the chemistry between couples and within the video. At certain moments, Tegan and Sara are the only ones in the living room, singing and dancing in an empty room only filled with balloons. Other times, the extras are in the background jumping and dancing, and having a blast. The camera jumps from one setting to another frequently; from the house party to a backyard or park, where Tegan and Sara are singing on swings, back to the living room, then to the duo lying on a trampoline. All of these backdrops are meant to remind the viewer of their high school years and take them on a journey to the past along with Tegan and Sara.

"Against the music, objects can seem to be reduced to a mood or flavor or speed..." (Vernallis 106). The television set is an important prop in this music video, yet with the sound, lyrics, and other distractions within the video, it can be overlooked. It is obvious that the TV looks like one from the 90s. Its size, colour, style, and accompanying VCR take the viewer back at least a decade. However, it is more important to note what is being shown on the TV. Only certain lyrics are displayed on the screen placing emphasis on "Come a little closer", "Oh so typical" and "I want you close / I want you". Furthermore, unlike in the previous two music videos, Tegan and Sara do not interact with any instruments and instead "(Instrumental)" is 
written on the TV. This implies that they do not feel the need to prove themselves as musicians any longer.

\section{Body/Gestures/Expressions}

Frith examines the role of the body in our understanding of musical performance and musical response. He refers to Paul Eckman, an American psychologist, and his three forms of socialized body movements.

First there are direct physical expressions of emotional states - fear, ecstasy, delight, anger, aggression, timidity, and so forth;[...] second, there are what Eckman calls "illustrative movements," movements tied to the content of a verbal narrative, to the flow of speech;[...] finally there are emblems, symbolic body movements which have specific (often verbal) meanings that can only be understood by people who know the interpretive rules. (Eckman qtd. in Performing Rites 217)

In the "Closer" music video, viewers definitely see more socialized body movements than in "The First" and "Back In Your Head" music videos. Some physical expressions include ecstasy and delight, along with excitement, romance and passion. There are a number of "illustrative movements" throughout this music video. For one, the title of the song and repeated lyric "closer" is emphasized while the male and female individuals flirt, touch and laugh together. I will not address the symbolic body movements because only those with insight to the specific meanings, who know the interpretive rules, will recognize them. Some of the women in the video are shown jumping up and down, and throwing pillows at one another, creating a feminine slumber party ambience. Tegan and Sara are also seen jumping on the trampoline in 
slow motion. Overall there is a lot more movement in this music video than in either of the previously discussed videos, displaying the musicians' bodies and femininity.

"Gender display, as an aspect of nonverbal behaviour, includes touch, facial expressions, eye contact, gestures, and posture" (Wallis 161-2). Tegan has a unique expression when she sings the word "closer". The right corner of her mouth looks as though it is being pulled up by an invisible piece of string and her eyes widen, as her pitch gets higher. As she sings "All you think of lately / Is getting underneath me-eeh!" the expression on her face teases and entices the viewer to think about what she is saying. Sara's eyes are frequently closed while she sings, as if she is too shy to face the camera or afraid to take away from Tegan being the centre of attention, as she is the one who wrote the song. However, Sara also looks up at the camera at times, with a sultry look in her eyes as if flirting with the camera. That innocent look in her eyes with her head tilted slightly to the right, and her pursed lips, is a recognized form of gender display. While Sara sings seductively to the viewer, Tegan lays on a floral couch behind her, with her head tilted back and her right leg bent, looking extremely comfortable and sexual.

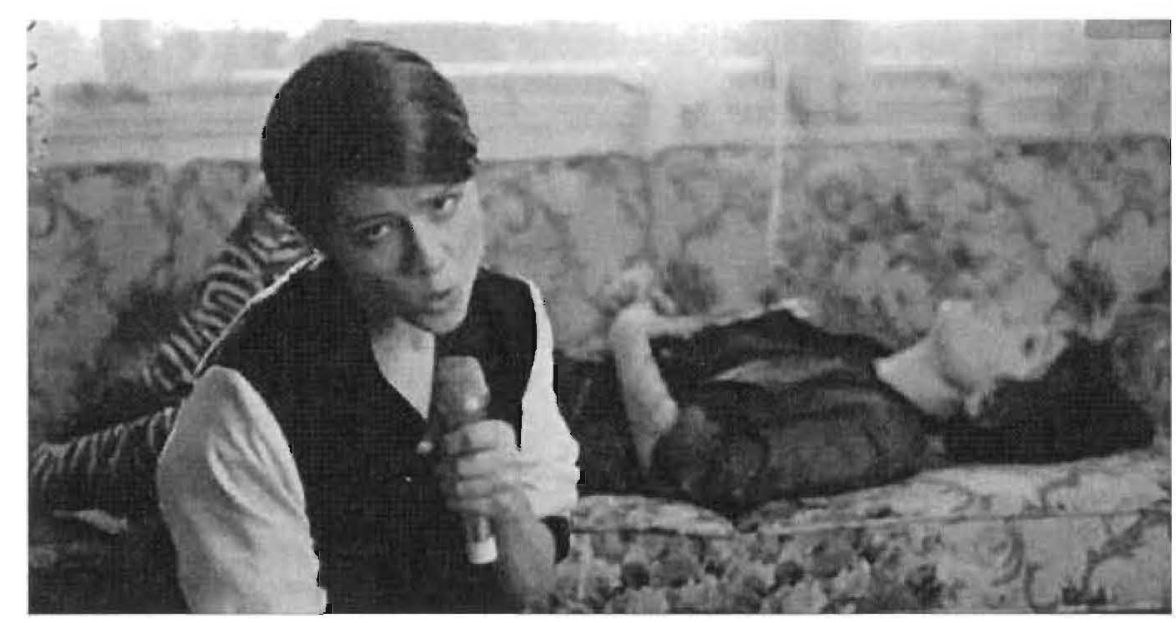

Image 6 
At 2:23 the video alternates between shots of two females, a female and a male, and two males, facing each other in the middle of a room, drawing on each other's faces with red lipstick and holding each other's heads intimately. They kiss on the lips sexually but tastefully. A couple interlaces their fingers together while laying in the fort. A female with short hair, (who could be mistaken for a male based on the way she is dressed), is expressively swaying an electric guitar up and down. The extras take turns jumping on the trampoline in pairs or groups of three. Near the end of the music video, a couple is sitting on a car, their legs and hands touching shyly. The woman is wearing a white dress and the boy is in jeans and a camouflage jacket. They glance at each other nervously, her leg swaying back and forth hinting at him to kiss her. He begins kissing her and suddenly multiple edits of couples of same and opposite sex couples are sitting on the car kissing. Arguably, this music video is filled with gender and sexuality displays, and while we do not see Tegan and Sara flirting with or kissing anyone in the video, the images imply that they are no longer trying to conceal their sexual orientation, but are embracing it.

Style

In the very first scene of the "Closer" video a hand inserts a video into a video cassette player and the old TV box displays a blue screen with the words:

\section{"CLOSER"}

Performed in the style of

\section{TEGAN \& SARA}

Hence, while we know that this music video was directed by Isaac Rentz, it is clear that Tegan and Sara participated in the production and styling of the "Closer" music video. 
"Costuming can function as an intermediary between the dance and the music; in music video, it can complicate our reading of the body and sound" (Vernallis 102). In an interview with Duncan Cooper, Sara explains how she found a pair of see-through polka dot tights in Tegan's closet that she immensely liked, and wanted to try wearing them for their music video. "I was like, I don't know, this feels very feminine and I'm not sure if I really understand it or feel it" (Cooper). After trying them on, Sara thought they were the most comfortable pants she had ever worn, and since then it has been her new thing. "I'm a 30-year old woman who's never worn tights. It's really confusing. When people notice I'm like "Yes! Thank you! Thank you for objectifying me, this one time"'” (Cooper). Cooper points out that Sara being objectified does not seem very novel, but she disagrees.

It is novel, because I think it's about the specific type of objectification that happens for us. We've been very conscious of not exploiting our sexuality. Or exploiting what we look like, because I think in today's society it's very institutionalized that if you become too much about something to look at and to observe as a woman, people just assume that your art has less value or that you're being duped or something (Cooper).

This statement seems contradictory to the "Closer" music video. While Tegan and Sara maintain that they consciously make an effort of not exploiting their sexuality, sexuality can be exploited in various ways. Their music videos are a reflection of who they are as a band. The individuals in their music video participate in gender and sexuality displays, and as part of their music video, they become a part of Tegan and Sara's image.

Tegan and Sara's hair is also more feminized than in the previous videos. Tegan's hair has a natural wave to it and Sara's is slicked straight. Tegan is wearing round black earrings, a black leather jacket, and black and white, zebra patterned leggings. Sara is similarly wearing a 
leather jacket, but with beige sleeves, and polka dot leggings. "More than advancing a story, clothing can serve to mark off the boundaries between performer, supporting characters, and viewer" (Vernallis 100). The other females in the video are wearing 90 s party dresses. Based on the set and the individuals' attire, it is likely that the party is a prom or graduation. Everyone is happy, celebrating, dancing, kissing and jumping around. While this video portrays slightly modern versions of the 90 s fashion styles, Tegan and Sara seem to have adopted this style as their current trend. Keeping in mind that the theme of Heartthrob is nostalgic yet upbeat, these performers use the creation of the "Closer" music video to introduce their evolving mode of fashion, giving the impression of a "bad-ass" enthusiastic duo.

The extras in the music video seem to have the same amount of camera time as Tegan and Sara, making the video about the high school party and exploration of sexuality, rather than solely focusing on the two artists and portraying them as professional musicians. Some of the individuals are applying make-up on each other's faces in the bedroom, and a female is applying lipstick on a male, although it is difficult to make gender classifications as both males and females are dressed similarly and have various lengths and styles of hair.

\section{Aesthetics}

"Music videos can return us to simple pleasures, like the exploration of space, as narrative is pushed aside" (Vernallis 110). In "Closer" Tegan and Sara and the director create a space that brings the viewer back to the 90 s, perhaps encouraging them to reminisce about their experiences during that time. The colourful balloons and dresses create a party-like ambience; however, the dimmed lights and sheer rose and gold coloured cloths making up the fort create a romantic mood. "We went for a softer, early 90s, pastels look," explains the 
director, Isaac Rentz. "We tried out a bunch of different colors and patterns to make sure it had the right atmosphere" (Kingler).

The camera frequently jumps to and from various settings, including the living room, bedroom, swing set, trampoline, couch, car, and back again. The video is in continuous motion. Even when the couples are standing on one spot applying make-up and kissing, the camera revolves around them. Compared to "The First", and even to "Back In Your Head", this music video includes a great deal more people, props, costumes, sets, and movement. The production level is expectantly much higher than for their videos that were produced seven or thirteen years ago.

\subsubsection{Creative Contribution}

"Music video directors seem also to replicate the songwriting process, turning first to music, then to lyrics" (Vernallis 138). They often listen to the music first imagining to what kind of place the music may go and how the camera would move or how it makes him or her feel. On Isaac Rentz's home page, he describes Tegan and Sara wanting to capture the complex feelings of joy, anxiety, and awkwardness of young lust, in a video that found inspiration in moments from their own childhood. "A motion control effect was employed during the choruses to visualize the universal desire for closeness. Real couples were cast to bring an authentic intimacy to the scenes" (Isaac Rentz).

Tegan and Sara approached Isaac Rentz and said, "we've never done a proper looking music video. All our music videos are very concept driven, very artistic, very arts and crafts" (Klinger). They wanted to keep it edgy, but to do something that introduced them to an audience outside of their fan base, according to Rentz. He wrote a treatment for the video that captured a universal feeling of young love. It seems like the director was the primary person 
in control of the making of this video, although Tegan and Sara approved of the tone, and final result. "At one point, the label said, 'it's done, give it to us! We're ready to put it out.' And [Rentz] said, 'No, it's not! Give us another week.' And they did, which is rare" (Klinger).

\subsection{4 "Closer" Summary}

Based on this song's sexual lyrics and the music video's all encompassing gender/sexual displays of both sexes, including straight and queer individuals, it is evident that the "Closer" music video relates to Tegan and Sara's own sexual orientation. Looking back on their "The First" music video where their sexuality was perhaps unintentionally conveyed with a more masculine look, it is clear that with "Closer" Tegan and Sara embrace their femininity and sexual orientation. Now that the novelty of their sexuality has subsided, they feel at ease to deliberately incorporate various sexual groups and behaviours in their music videos. The combination of Tegan and Sara's first and last music videos, along with various interviews that they have been a part of over the years, feels contradictory at times. Back in 2000 , they lacked femininity, they wanted to make music for the masses, and they were against gender stereotypes and sexual exploitation. Today, they have acquired a more feminine look, are seeking a new audience, and will accept certain objectifying comments. "We've made everything different," explains Tegan (Marchese). 


\section{Chapter IV: MAKING THE CONNECTION}

The theories, interviews, and music video analyses in this paper have greatly contributed to answering the questions: to what extent do Tegan and Sara's music videos demonstrate their public identity, and to what degree do Tegan and Sara adhere to conventional nonverbal gendered behaviour in the their music videos? As I predicted, gender and sexuality are displayed in the examined music videos. Although Tegan and Sara's public identity has evolved over the years, it has consistently been present in their videos. While the signs attached to their actions have evolved, along with society's understanding of these signs, Tegan and Sara do in some form or another demonstrate nonverbal gendered behaviour both deliberately and unintentionally.

The case study analysis of the three music videos "The First", "Back In Your Head", and "Closer" has created a general outline of the narrative structure of Tegan and Sara's musical career, and the evolution of their public identity. With an initial aim to conceal and ignore their sexuality, for the purpose of representing themselves as "a real band, playing real music" (Cooper), Tegan and Sara piqued their audience's curiosity, by taking on the role of the stereotyped masculine female. With “The First's" somber lyrics, low pitch, and monotonous tone, along with the music video's casual set and Tegan and Sara's androgynous fashion style, one can conclude that the efforts made to suppress their femininity did not go unnoticed, and instead brought their sexuality, or lack there of, to the viewers' attention even more so.

Seven years later, Tegan and Sara's sound and image had changed drastically. Not only did they write and play their music in a much higher key, but their style also emphasized their femininity. It seems that as they began to gain fans and their respect, they started to care less about how they were perceived as female artists. "Now that l'm older, I don't care what people 
think. And it's on our terms and it's in a way that feels comfortable for us. I don't feel like l'm acting or playing a role that isn't actually how I am in my real life" (Sara qtd. in Cooper). Whether this statement is true or not, it implies that when they were younger, and first starting out as musicians, they cared more about what people thought and therefore did act or play a role.

Today, it seems that Tegan and Sara have completely altered their approach and created new goals and public identities for themselves. With their first two albums, and first few music videos, they were primarily concerned about gaining fans; any fans. Once they acquired a fan base, they worried that some of their fans only saw them as queer role models and were only interested in their personal lives and sexual orientation. In more recent interviews Tegan and Sara note that they think the media has finally shifted their focus away from their sexuality and toward their music, hence they feel safe discussing it publicly ("On The Hour $\left.(\mathrm{CBC})^{\prime \prime}\right)$. With the evolution of their sound and image, Tegan and Sara are looking to reach a whole new audience. "Tegan and Sara haven't been quiet about the fact that a big goal of the new sound is to sell more records and reach a new fan base" (Pelly).

It is challenging to determine the extent to which their decision to stop caring about what people think and focus on selling records is truly theirs, or their record label's. However, it is clear that as an indie band, acting as their own managers and having full control of their sound and image, Tegan and Sara were persistent in having the public view them as serious musicians without a sexuality. Now that they are with a big record company, and wish to appeal to a new and greater audience, they have become open to the idea of exploring and exploiting their gender, sexuality, and public image.

What does the future hold in store for Tegan and Sara? 
If Heartthrob goes the way I want it to, which [is that it] will be our biggest and our best record, then I see us continuing to make records. And they are going to sound different than Heartthrob and all of our other records. I think we will continue to evolve. (Tegan qtd. in Greene 2)

By "continuing to evolve", I think Tegan means that they will continue to pursue new and bigger audiences by playing up their image. Their brand has become their unique blend of being Canadian, and being queer twins, and they will use this to their advantage in selling records. Other bands have followed a similar suit. Many start off in a niche music category and as they gain publicity and momentum they need to cater their look and sound to a greater audience to sell more records. Sometimes this requires exploiting their sexuality.

Looking back on my research and analysis, there were certainly some challenges that arose along the way, and aspects of the process I would have done differently. While it is important to assess the band's history, including their music, style, and the way they have evolved, when trying to establish their public identity and how it is portrayed, given more time, it may have been more beneficial to include a greater sample size of Tegan and Sara's music videos for the analysis, in order to illustrate their process of change in greater detail. Moreover, I would have liked to compare Tegan and Sara's public identity and the way it is portrayed and perceived in the media, to that of another Canadian band, such as The Tragically Hip. This was my initial objective, however, due to the myriad of information gathered solely on Tegan and Sara, I felt it would be more manageable and appropriate to focus on them alone in this paper. The main challenge of this paper was deciphering what Tegan and Sara meant in some of their interviews. Without knowing whether their behaviours were genuine or not, deliberate or unintentional, it has been difficult to truly understand what 
they intended when they said that they do not want their audience to focus on their sexuality. This statement can mean that as musicians they do not want to present their sexuality, or that they do not want it to overshadow their music. In the end, it is still visually evident how their approach to take the focus away from their sexuality has evolved. It is clear that gender and sexuality are displayed in Tegan and Sara's music videos, therefore this portrayal of sexuality must be recognized and created with awareness by the band. While the two artists have a personal blog to ensure their true voices are heard, it is important to be reminded that images can be more powerful than words, and for them to consciously decide the kind of public identity they wish to create through their music videos. 


\section{Appendix I: "The First" Lyrics from This Business of Art (2000)}

\section{Verse 1:}

Stand up sit down baby

Gonna be a formal dress down hey day

We decide why not go downtown

How about you and me we go get wasted

You'll have, you'll have to excuse me

Please please, please excuse me

You'll have, you'll have to excuse me

This will be my first time

By definition from grade school to English 30

We quietly become strong so early

Take it or leave it

They can't believe it

They go from kindergarten to killing sprees

They go from heartache to inner peace 100 foot ceilings 100 percent deceit

He said let's leave this between you and me

My cats watch my stuff leave my house

Between you and me the cat burglars are

What did you see what did you steal

Tell me baby how does it feel

Yeah how do you feel

It's a top ten list of

Things that move me the most

It's a top ten list of

Things that bother me the most

A top ten list of

Things that scare me the most

I'd have to say that the future

Wasting time in the fast food line

I decide to walk the fine line

And celebrate life celebrate death

Pre chorus:

I choose to celebrate the first

I celebrate the first

We decide to go out walking

The whole time that we're talking

Convinced that we're living

The whole time that we're dying
We decide to go out walking

The whole time that you're talking

Convinced that you're living

Whole time that I'm dying

\section{Chorus:}

Keeps me on my toes

Where did the time go

You keep me on my toes

Where did the time go

On the edge of town where the gravel's thin

\section{Verse 2:}

They're gonna wear you down

Until you're thin and tired tired tired

of wasting time in the fast food line

I decide to walk the fine line

And celebrate life celebrate death

I choose to celebrate

The first to come the first to go

The first to say yes the first to say no

I'm gonna seize this moment

The first to come the first to go

Pre chorus:

The first to say yes the first to say no

We decide to go out walking

The whole time that we're talking

Convinced that we're living

Whole time that we're dying

\section{Chorus:}

Keeps me on my toes

Where did the time go, yeah

Keeps me on my toes

Where did the time go

You keep me on my toes

Where did the time go

You keep me on my toes

You keep me on my toes

You keep me on my toes 
Appendix II: "Back In Your Head" Lyrics from The Con (2007)

Verse1:

Build a wall of books

Between us in our bed

Repeat, repeat the words

That I know we both have said

Relax into the need

We get so comfortable

Remember when I was

So strange and likable

\section{Chorus:}

I just want back in your head

I just want back in your head

I'm not unfaithful but I'll stray

\section{Tag:}

When I get a little scared

When I get a little scared

When I get a little

\section{Verse 2:}

When I jerk away

From holding hands with you

I know these habits hurt

important parts of you

Remember when I was

Sweet and unexplainable

Nothing like this person

Unlovable

\section{Chorus:}

I just want back in your head

I just want back in your head

I'm not unfaithful but I'll stray

Tag:

When I get a little scared When I get a little scared When I get a little scared When I get a little

\section{Bridge:}

Run, run, run, run

Run, run, run, run

I just want back in your head I just want back in your head I'm not unfaithful but I'll stray I'm not unfaithful but I'll stray I'm not unfaithful but I'll stray I'm not unfaithful but I'll stray 


\section{Appendix III: "Closer" Lyrics from Heartthrob (2012)}

\section{Verse1:}

All I want to get is a little bit closer

All I want to know is, can you come a little closer?

Here comes the breath before we get a little bit closer

Here comes the rush before we touch, come a little closer

The doors are open, the wind is really blowing

The night sky is changing overhead

\section{Chorus/Tag:}

It's not just all physical

I'm the type who will get oh so critical

So let's make things physical

I won't treat you like you're oh so typical

I won't treat you like you're oh so typical

\section{Verse2:}

All you think of lately is getting underneath me

All I'm dreaming lately is how to get you underneath me

Here comes the heat before we meet a little bit closer

Here comes the spark before the dark, come a little closer

The lights turned off and the sun if finally setting

The night sky is changing overhead

\section{Chorus/Tag:}

It's not just all physical

I'm the type who will get oh so critical

So let's make things physical

I won't treat you like you're oh so typical

I want you close, I want you

I won't treat you like you're typical

I want you close, I want you

I won't treat you like you're typical

\section{Bridge:}

Here come the dreams of you and me Here come the dreams

Here come the dreams of you and me

Here come the dreams

\section{Chorus:}

It's not just all physical

I'm the type who will get oh so critical

So let's make things physical

I won't treat you like you're oh so typical

I want you close, I want you

I won't treat you like you're typical

I want you close, I want you

I won't treat you like you're typical

I won't treat you like you're typical

I won't treat you like you're typical

\section{Outro:}

All I want to get is a little bit closer

All I want to know is, can you come a little closer? 


\section{Works Cited}

Ash, Amanda. "Tegan \& Sara Sister of Mercy." Exclaim.ca. Nov. 2009. Web. 8 Apr. 2013.

Bendix, Trish. "Tegan Quin wants to get "Closer"." AfterEllen.6 Sept. 2012. Web. 11 Mar. 2013.

Berland, Jody. "Sound, Image and Social Space: Music Video and Media Reconstruction." Sound and Vision: The Music Video Reader. London: Routledge. (1993): Ch. 2.

Cooper, Duncan. "Interview: Tegan and Sara" Fader. 28 Nov. 2012. Web. 27 Mar. 2013.

Frith, Simon. Performing Rites: Evaluating Popular Music. Oxford: Oxford University Press, 1998. Print.

Frith, Simon. Sound Effects: Youth, Leisure and the Politics of Rock ' $n$ ' Roll. London: 1983. Print.

Get Along. Dir. Danny O'Malley and Elinor Svoboda. Super Closer Music Inc. and Warner Bros. Records, 2011.

Goffman, Erving. The Presentation of Self in Everyday Life. New York: Anchor Books. 1959. Print.

Greene, Andy. "Q\&A: Tegan and Sara on Sibling Rivalry, Leaving the Indie World Behind: Sisters were "literally at blows with each other backstage'." RollingStone Music. 11 Jan. 2013. Web. 20 Feb. 2013.

"Interview with Tegan and Sara: Origins and Influences." YouTube. 5 Feb. 2013. Web. 27 Mar. 2013.

Klinger, Douglas. "Video Chats: Isaac Rentz on 'Closer' by Tegan and Sara." IMVDb. 13 Dec. 2012. Web. 20 Apr. 2013.

Lazowski, Anna. "Digging Into the Deep: Singer-songwriter Sara Quin Discusses Her Musical and Political Influences, and Muses About What the Future Might Hold for Tegan and Sara." Herizons. 24.1 (2010): 24. Web.

Marhese, David. "Tegan and Sara Reveal 5 Secrets Behind Their Seventh LP." SPIN. 5 Arp. 2012. Web. 12 Feb. 2013. 
Marcus, Sara. "Not Just a Sister Act." The Advocate. 937.58 (2005): n.pag. Web. 3 Mar. 2013.

Middleton, Richard. Studying Popular Music. Philadelphia: Open University Press. 1990. Print.

Morris, Jeremy. "The Person Behind the Music We Adore: Artists, Profiles, and the Circulation of Music." Journal of Mobile Media. 7.1. (2013). Web. 20 March, 2013.

"MuchMusic - Tegan and Sara on New.Music.Live." YouTube. 10 Jan. 2013. Web. 3 Feb. 2013.

Pelly, Liz. "The 10 Best Tegan and Sara Songs." Stereogum. 15 Feb. 2013. Web. 12 Apr. 2013.

"Q with Jian Ghomeshi: Tegan and Sara on Q TV." YouTube. 22 Dec. 2009. Web. 20 Feb. 2013.

Railton, Diane and Watson, Paul. Music Video and the Politics of Representation. Edinburgh: Edinburgh University Press, 2011. Print.

Rentz, Isaac. Director Home Page. Web. 20 Apr. 2013.

Rundle, Lusa. "Grrrls, Grrrls, Grrrls [Riot Grrl Movement]." Herizons. 19.1. (2005): 31. Web. 10 Apr 2013.

Seward Barry, Ann Marie. Visual Intelligence: Perception, Image, and Manipulation in Visual Communication. New York: State University of New York Press, 1997. Print. 264.

Schwartz, Jay. "Tegan and Sara Make Our 'Heartthrob'." OUT. 6 Feb 2013. Web. 20 Feb. 2013.

Shechet, Ellie. "Tegan and Sara's Tegan Quin on “Heartthrob," Sistelry Love, \& Homemade Hammer Pants." Bullet. 29 Jan. 2013. Web. 13 Mar. 2013.

Simmard, Magali. "Jamie Travis." blogTO. 7 Mar. 2010. Web. 2 Mar. 2013.

"Tegan \& Sara - About BIYH, Chris Walla@ Borders, Ann Arbor." YouTube. 12 Mar. 2008. Web. 12 Apr. 2013.

"Tegan and Sara Interview. Music-News.com, Heartthrobs." YouTube. 7 Feb. 2013. Web. 23 Feb. 2013.

Tegan and Sara Official Website: <http://www.teganandsara.com/> Web. 5 Feb. 
2013.

"Tegan and Sara On The Hour (CBC)". YouTube. 11 Feb. 2010. Web. 15 Feb. 2013.

“Tegan and Sara Quin in Studio Q." YouTube. 29 Jan. 2013. Web. 15 Feb. 2013.

Vernallis, Carol. Experiencing Music Video: Aesthetics and Cultural Context. New York: Columbia University Press, 2004. Print.

Wallis, Cara: "Performing Gender: A Content Analysis of Gender Display in Music Videos." Sex Roles: A Journal of Research. (2011). 64:160-172. Web. 


\section{Discography}

Tegan and Sara. "Back In Your Head." The Con. 2007.

Tegan and Sara. "Closer." Heartthrob. 2012.

Tegan and Sara. "The First." This Business of Art. 2000.

\section{Videography}

"Tegan and Sara - The First [Official Music Video]." YouTube. 17 Jun. 2010. Web. 20 Jan 2013.

“Tegan and Sara - Back In Your Head [Official Music Video]." YouTube. 13 Nov. 2007. Web. 20 Jan 2013.

"Tegan and Sara - Closer [Official Music Video]." YouTube. 29 Nov. 2012. Web. 20 Jan 2013. 